\title{
Effect of surface chemistry and roughness on the high temperature deposition of a model asphaltene
}

DOI:

10.1021/acs.energyfuels.9b00386

\section{Document Version}

Accepted author manuscript

Link to publication record in Manchester Research Explorer

\section{Citation for published version (APA):}

Shetty, P. P., Zhang, R., Haire, B., Smith, C., Kenny, L., Wu, T., Subramani, V., Quayle, P., Yeates, S., Braun, P. V., \& Krogstad, J. A. (2019). Effect of surface chemistry and roughness on the high temperature deposition of a model asphaltene. Energy \& Fuels . https://doi.org/10.1021/acs.energyfuels.9b00386

\section{Published in:}

Energy \& Fuels

\section{Citing this paper}

Please note that where the full-text provided on Manchester Research Explorer is the Author Accepted Manuscript or Proof version this may differ from the final Published version. If citing, it is advised that you check and use the publisher's definitive version.

\section{General rights}

Copyright and moral rights for the publications made accessible in the Research Explorer are retained by the authors and/or other copyright owners and it is a condition of accessing publications that users recognise and abide by the legal requirements associated with these rights.

\section{Takedown policy}

If you believe that this document breaches copyright please refer to the University of Manchester's Takedown Procedures [http://man.ac.uk/04Y6Bo] or contact uml.scholarlycommunications@manchester.ac.uk providing relevant details, so we can investigate your claim.

\section{OPEN ACCESS}


This document is confidential and is proprietary to the American Chemical Society and its authors. Do not copy or disclose without written permission. If you have received this item in error, notify the sender and delete all copies.

\section{Effect of surface chemistry and roughness on the high temperature deposition of a model asphaltene}

\begin{tabular}{|c|c|}
\hline Journal: & Energy \& Fuels \\
\hline Manuscript ID & ef-2019-00386n.R2 \\
\hline Manuscript Type: & Article \\
\hline $\begin{array}{r}\text { Date Submitted by the } \\
\text { Author: }\end{array}$ & 01-Apr-2019 \\
\hline Complete List of Authors: & $\begin{array}{l}\text { Shetty, Pralav; University of Illinois at Urbana-Champaign, Department } \\
\text { of Materials Science and Engineering; University of Illinois at Urbana- } \\
\text { Champaign, Frederick Seitz Materials Research Laboratory } \\
\text { Zhang, Runyu; University of Illinois at Urbana-Champaign, Department } \\
\text { of Materials Science and Engineering; University of Illinois at Urbana- } \\
\text { Champaign, Frederick Seitz Materials Research Laboratory } \\
\text { Haire, Barnaby; University of Manchester, School of Chemistry } \\
\text { Smith, Charles; University of Illinois at Urbana-Champaign, Department } \\
\text { of Materials Science and Engineering; University of Illinois at Urbana- } \\
\text { Champaign, Frederick Seitz Materials Research Laboratory } \\
\text { Kenny, Liam; University of Illinois at Urbana-Champaign, Department of } \\
\text { Materials Science and Engineering } \\
\text { Wu, Tiffany; University of Illinois at Urbana-Champaign, Department of } \\
\text { Materials Science and Engineering } \\
\text { Subramani, Velu; BP America Inc Naperville, Refining Technology } \\
\text { Quayle, Peter; University of Manchester, Chemistry } \\
\text { Yeates, Steve; University of Manchester, Chemistry } \\
\text { Braun, Paul; University of Illinois at Urbana-Champaign, Materials } \\
\text { Science and Engineering; University of Illinois at Urbana-Champaign, } \\
\text { Frederick Seitz Materials Research Laboratory; University of Illinois at } \\
\text { Urbana-Champaign, Beckman Institute for Advanced Science and } \\
\text { Technology } \\
\text { Krogstad, Jessica; University of Illinois at Urbana-Champaign, } \\
\text { Department of Materials Science and Engineering; University of Illinois at } \\
\text { Urbana-Champaign, Frederick Seitz Materials Research Laboratory }\end{array}$ \\
\hline
\end{tabular}

\section{SCHOLARONE Manuscripts}




\begin{abstract}
Fouling of processing units because of asphaltene deposition is a common phenomenon that interrupts the operation of oil refineries. In this study, the deposition behavior of a model archipelago asphaltene was investigated in the temperature range of $150{ }^{\circ} \mathrm{C}$ to $350^{\circ} \mathrm{C}$. For a fixed surface chemistry, the differences in deposit chemistry with fouling temperature is a function of the thermochemical properties of the model asphaltene. Under static high pressure and high temperature fouling conditions, both surface roughness and chemistry play an important role in asphaltene deposition. Rough surfaces are shown to develop larger deposits because of less restrictive physical barriers to inhibit deposit growth. Passivating the surface with an alumina chemistry significantly reduces the impact of surface roughness, as well as the total amount of deposition. This beneficial effect of using a protective alumina chemistry is attributed to its high thermal stability and low diffusivity that inhibit the uncontrolled formation of thiolate and sulfide deposits that are found on unpassivated steels. Instead, alumina modifies the surface reaction to a self-limiting chemisorption and oxidation process that produces thin sulfate deposits at the surface. With further consideration to the reactive species present in solution, the findings of this study may be extended to determine suitable surface conditions that mitigate asphaltene fouling.
\end{abstract}

Prepared for submission to ACS Energy \& Fuels, February 2019

*Corresponding author: Jessica A. Krogstad, E-mail: jakrogst@illinois.edu 


\section{INTRODUCTION}

Asphaltenes are the heaviest fraction within the aromatic composition group of petroleum. ${ }^{1}$ They are known to destabilize, precipitate, and foul petroleum production surfaces. ${ }^{2}$ Changes in operating temperature and pressure can further exacerbate the fouling process. ${ }^{3}$ Asphaltenes are commonly grouped by molecular structural motifs including island ${ }^{4}$ and archipelago ${ }^{5,6}$ type and may include a variety of heteroatomssulfur, nitrogen, and oxygen are the most common and consequential. ${ }^{7}$ It has proven challenging to determine more specific structures ${ }^{8,9}$ and varieties of asphaltenes ${ }^{10}$ beyond such generic designations. As a result, elucidating the surface interactions that drive asphaltene fouling has also remained elusive.

Treating the surfaces ${ }^{11,12}$ in contact with petroleum to inhibit asphaltene deposition is one of many proposed methods to control fouling. ${ }^{13-15}$ Several key surface properties dictate interactions with the environment. In asphaltene fouling, surface roughness ${ }^{16}$ and surface chemistry ${ }^{17}$ have been identified as critical surface descriptors. Importantly, surface roughness and chemistry are not always independent, nor do they remain constant over the term of service. For example, rough surfaces may be more prone to deposition because of nonuniform chemistry or concentrations localized to surface features of different dimensions. Smooth surfaces, on the other hand, may gradually roughen through the formation of corrosive products. Previous studies postulate that corrosion may induce fouling; ${ }^{18}$ however mechanisms underlying this correlation remain tenuous because of a lack of systematic studies on well characterized surfaces fouled in controlled environments.

Without mechanistic guidance, it remains difficult to identify surface preparations that can effectively mitigate high temperature asphaltenic fouling. However, drawing upon insight from other corrosive environments, it is possible to identify properties of surface coatings or passivating scales most likely to result in enhanced fouling resistance. These properties include: chemical inertness, limited/sluggish mass transport kinetics, thermal stability, and mechanical robustness. Intentionally oxidizing an alloy surface with protective oxides may be one route to achieve these properties. 
Alumina has been shown to serve as an effective diffusion barrier against corrosive media. ${ }^{19-21}$ While perhaps more frequently employed in a crystalline form, ${ }^{22-24}$ even in its amorphous form, alumina coatings have been shown to reduce corrosion in an $\mathrm{NaCl}$ environment by up to four orders of magnitude. ${ }^{25}$ Likewise, a native amorphous alumina has been shown to have a low asphaltene affinity. ${ }^{26}$ Because of these desirable properties several techniques have been developed to both grow ${ }^{24,27}$ and deposit ${ }^{28-30}$ alumina on alloys in a controlled manner.

A recent review by Adams ${ }^{31}$ summarizes numerous studies on asphaltene fouling of metals and their oxides (including alumina), which have used asphaltenes extracted from petroleum and ambient conditions to generate adsorption isotherms. In parallel with these efforts, several computational research groups have successfully modeled the miscibility, ${ }^{32}$ asphaltene-asphaltene interactions, ${ }^{33}$ and aggregation ${ }^{34}$ of model asphaltene molecules. However, the paucity of relevant, elevated temperature experimental data with model asphaltenes has hindered extension of these modeling efforts to include asphaltene-surface interactions. This is especially important because the change in operating conditions during the petroleum production chain may result in a change in the thermochemical properties of the asphaltenes. This in turn could give rise to alternate asphaltene deposition mechanisms.

In this study, high pressure and high temperature (HPHT) fouling experiments were carried out using a sulfur-containing model archipelago asphaltene. The well characterized model asphaltene was used to reduce the number of high-temperature surface reaction mechanisms. Both stochastically and deterministically roughened surfaces with and without alumina passivation were studied. This allowed for a systematic investigation of the effect of surface properties (roughness, chemistry) on the morphology and chemistry of the deposits. In order to understand mechanisms of asphaltene deposition at high temperatures, the work presented herein explores the link between asphaltene properties, testing conditions, and the nature of deposition on surfaces. The insights gained from this work have the potential to motivate surface engineering approaches that may mitigate more complex forms of asphaltene deposition with careful consideration to the reactive species present in solution. 


\section{METHODS}

\section{A. Synthesis and characterization of the model asphaltene}

The model asphaltene used in this study is 1,6-bis(pyren-1-ylthio)hexane, denoted as BPH. All reactants and reagents were purchased from Sigma Aldrich, Fisher Scientific, Acros Organics, Apollo Scientific, or Fluorochem. The model asphaltene was synthesized using a nucleophilic aromatic substitution reaction. A mixture of 1-bromopyrene (500 mg, $1.78 \mathrm{mmol}$ ), potassium carbonate (5 eq.), and $\mathrm{N}, \mathrm{N}$-dimethylformamide was sparged with argon in a Schlenk tube for 10 minutes. An addition of 1,6-Hexanedithiol (127.4 mg, 0.847 $\mathrm{mmol}$ ) was made to the mixture followed by heating to $140{ }^{\circ} \mathrm{C}$ for 16 hours under a $\mathrm{N}_{2}$ atmosphere. The crude reaction mixture was then diluted with toluene and the organic layer was washed (water then brine), dried $\left(\mathrm{MgSO}_{4}\right)$, and concentrated in vacuo. The residue was purified by recrystallization from heptol (50 - 50 vol. \% n-heptane and toluene) to synthesize BPH as an amorphous yellow-colored solid. The yield of this process was measured to be $333 \mathrm{mg}(34 \%)$.

The structure of BPH was deduced using Nuclear Magnetic Resonance (NMR) [Bruker Avance III 400, Bruker Corporation]. The ${ }^{1} \mathrm{H}$ and ${ }^{13} \mathrm{C}$ NMR spectra were referenced to the residual solvent peak of deuterated chloroform $\left(\mathrm{CDCl}_{3}, 7.27 \mathrm{ppm}\right.$ or $77.00 \mathrm{ppm}$ respectively). Thermogravimetric analysis (TGA) [Q50, TA Instruments] and differential scanning calorimetry (DSC) [Discovery 2500, TA Instruments] of BPH were conducted in a $\mathrm{N}_{2}$ environment to establish its baseline thermochemical behavior. A ramp rate of $10{ }^{\circ} \mathrm{C} / \mathrm{min}$ was used for both TGA and DSC measurements. For the TGA measurement, $\mathrm{BPH}$ was heated to $800^{\circ} \mathrm{C}$ from room temperature. For the DSC measurement, $\mathrm{BPH}$ was heated from $25^{\circ} \mathrm{C}$ to $200{ }^{\circ} \mathrm{C}$, cooled back down to $25^{\circ} \mathrm{C}$ and then heated back up to $200^{\circ} \mathrm{C}$. The second heating curve has been reported. Finally, a single crystal X-ray structure determination not only confirmed the constitution of BPH but also provided insights into its packing in the crystalline state (see Supplementary Information). 


\section{B. Metallographic surface preparation and alumina passivation}

A high strength low alloy pipe steel (API 5L X65) [European Corrosion Supplies Ltd., cf Table I for full composition] was cut into $5 \mathrm{~mm} \times 5 \mathrm{~mm} \times 0.5 \mathrm{~mm}$ coupons using electrical discharge machining (EDM). The coupons were polished to a smooth but stochastic finish (average roughness of $24.3 \pm 14.9 \mathrm{~nm}$ ) using silicon carbide grinding and a $1 \mu \mathrm{m}$ neutral alumina polishing solution. In order to intentionally roughen the surface in a stochastic manner, following a rough (600 grit) polish to remove EDM damage, grit blasting with alumina particles was used (average roughness of $2383.6 \pm 514.3 \mathrm{~nm}$ ). All coupons were sonicated in acetone, isopropanol, and deionized water for $1 \mathrm{~min}$ each and then dried with a $\mathrm{N}_{2}$ gun prior to HPHT fouling.

To generate meaningful correlations between surface features and deposit morphology, monolayer nickel inverse opals (IOs) with a well-defined surface geometry were electrodeposited on gold coated sapphire substrates. As outlined in Fig. 1 (a)-(d), polystyrene spheres were self-assembled on a gold coated sapphire substrate, followed by electrodeposition of $\mathrm{Ni}$ to half the sphere diameter, and dissolution of the polystyrene. More details about the electrodeposition conditions of the IOs can be found in a previous study. ${ }^{35}$ The average roughness of the 10 s was selected to be $250 \mathrm{~nm}, 500 \mathrm{~nm}$, and 800 $\mathrm{nm}$ by varying the polystyrene sphere diameter.

(a)

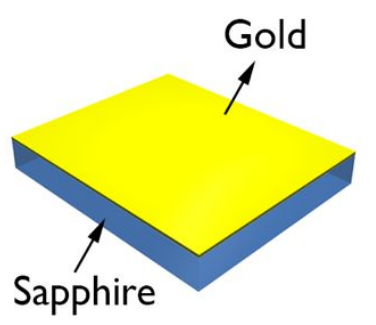

(b)

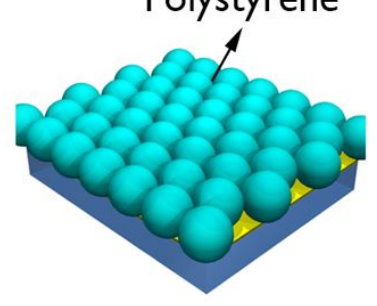

(c)

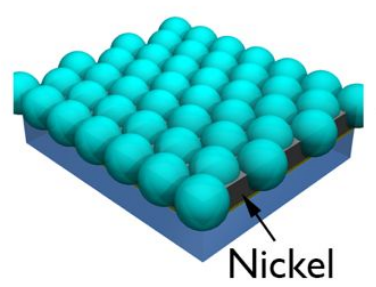

(d)

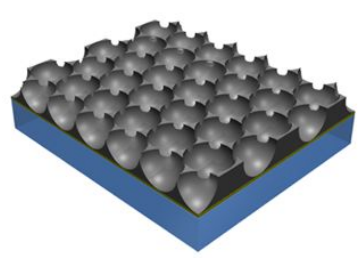

Fig. 1: Method used to fabricate monolayer nickel inverse opals. (a) Gold was electron beam evaporated onto sapphire to make it conductive, (b) polystyrene spheres were selfassembled on the gold coated sapphire, (c) nickel was electrodeposited into the voids between polystyrene spheres to half the height of the monolayer, and (d) the polystyrene spheres were dissolved to produce the desired nickel structure for further atomic layer deposition alumina passivation. 
Table I. Chemical composition of as-received X65 steel in atom percent.

\begin{tabular}{ccccccccc}
\hline $\mathbf{F e}$ & $\mathbf{C}$ & $\mathbf{S}$ & $\mathbf{M n}$ & $\mathbf{P}$ & $\mathbf{S}$ & $\mathbf{V}$ & $\mathbf{N b}$ & $\mathbf{T i}$ \\
\hline Bal. & 0.16 & 0.45 & 1.65 & 0.02 & 0.01 & 0.09 & 0.05 & 0.06 \\
\hline
\end{tabular}

The surfaces of certain X65 coupons and the IOs were passivated using atomic layer deposition (ALD) alumina [Savannah S100, Cambridge Nanotech]. In addition to the standard cleaning procedure mentioned in Section II. B., all surfaces were cleaned in a UV/Ozone cleaner for 10 min per side, prior to ALD deposition. The X65 substrates were passivated to provide a different surface chemistry and the IOs were passivated to also improve the thermal stability of the nickel structure that is prone to thermal creep. Amorphous ALD alumina films were grown using water and trimethylaluminum at a growth temperature of $80^{\circ} \mathrm{C} .{ }^{28}$ Conformal alumina films from $0.5 \mathrm{~nm}$ to $30 \mathrm{~nm}$ in thickness were grown as passivation layers for the HPHT fouling test. On the rough X65 coupons, the alumina coating provided a different surface chemistry without significantly changing the surface roughness $(2013.0 \pm 321.7 \mathrm{~nm}$ on the rough substrates).

\section{HPHT fouling test and surface characterization}

Since $\mathrm{BPH}$ is aromatic, it is soluble in toluene and insoluble in heptane. Thus, a stock solution of $0.22 \mathrm{wt}$. \% BHP in toluene was prepared. Next, $2.5 \mathrm{ml}$ of the stock solution was thoroughly mixed by sonication for $30 \mathrm{~min}$ and equal parts by volume of heptane was added prior to the HPHT fouling test. The final makeup of the surrogate fuel was $0.125 \mathrm{wt}$. \% of BPH in the heptol solution.

An autoclave [60 ml EZE Seal Pressure Vessel, Parker Hannifin] made from 316 stainless steel was used to conduct the HPHT fouling test. Heat treatments were conducted with the samples submerged vertically in the surrogate fuel to limit gravitationally assisted deposition. A drawing of the mount used to suspend samples vertically during HPHT fouling is shown in Fig. 2. It consisted of three sets of slits to hold samples and a large groove to avoid gravitational deposits from collecting near the 
bottom of the sample. The autoclave was air-sealed with $5 \mathrm{ml}$ of the surrogate fuel for heat treatments at either $150^{\circ} \mathrm{C}$ or $350^{\circ} \mathrm{C}$. A ramp rate of $10^{\circ} \mathrm{C} / \mathrm{min}$ was used starting at room temperature, followed by a 1 hour hold, and finally a furnace cool to room temperature. A gentle post-fouling pipette rinse with $1 \mathrm{ml}$ petroleum ether per side removed loosely adhered deposits.

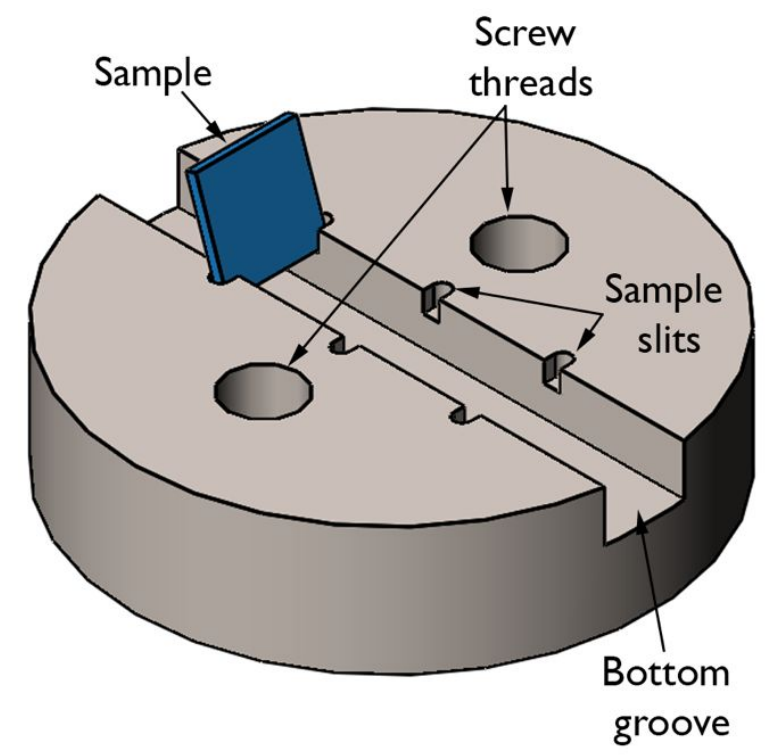

Fig. 2: Custom sample mount for the high pressure and high temperature fouling tests. The design of the mount includes three sets of slits to hold samples within $5^{\circ}$ from vertical, a groove to avoid gravitational deposits from collecting near the bottom of the sample, and screw threads to help transfer the mount.

The amount of deposit mass gained was measured using a microbalance [XPE26, Mettler-Toledo]. All mass gains are reported as area normalized values in order to compare the performance of different surface preparations. It is challenging to measure the exact surface area of a microscopically rough surface even with a full 2D dataset of its surface topography. ${ }^{36}$ In this work, 1D scans of the surface were collected and thus a few assumptions were made to estimate the surface area. First, the surface area was linearly interpolated based on the projected surface area and the measured surface roughness as shown in Eq. 1. This relationship can be derived since the surface area of a perfectly smooth sample is equal to the projected area, and that for a stochastically 
rough (grit blasted in this case) sample can be estimated based on its surface topography measured with a contact profilometer [Dektak ${ }^{3} S T$, Veeco Instruments, Inc.].

$$
\begin{aligned}
\text { Surface area }\left[\mathrm{mm}^{2}\right]= & \text { Projected area }\left[\mathrm{mm}^{2}\right]+ \\
& 2.8 \times 10^{-3}\left[\mathrm{~mm}^{2} / \mathrm{nm}\right] \times \text { Average roughness }[\mathrm{nm}]
\end{aligned}
$$

A $1 \mathrm{~mm}$ scan length was used for all roughness measurements. The average roughness is reported as the average absolute value of deviation from the mean line. All roughness measurements were made before the HPHT fouling. The deposit morphology was evaluated using scanning electron microscopy (SEM) [Hitachi S-4800, Hitachi Ltd.] and scanning transmission electron microscopy (STEM) [JEOL 2010F S(TEM), JEOL Ltd.].

The top layer deposit chemistry was identified using $\mathrm{x}$-ray photoelectron spectroscopy (XPS) [Kratos Axis Ultra photoelectron spectrometer, Shimadzu Corporation]. For XPS, a monochromatic $2 \mathrm{~mm} \times 2 \mathrm{~mm} \mathrm{Al} \mathrm{K}_{\alpha}$ excitation source was incident on the sample to generate photoelectrons. The analyzer optics were set to analyze a $0.3 \mathrm{~mm} \times 0.7 \mathrm{~mm}$ region of the sample. The pass energy was set to $40 \mathrm{eV}$ and an average over six scans of the bands of interest is reported. The XPS data were analyzed using a CasaXPS software package and peak fitting was conducted with a Shirley background subtraction. The baseline surface interactions of BPH with the X65 and alumina passivated surfaces was also determined using XPS on samples that were dipped in the surrogate fuel for 48 hours at room temperature.

For the deposits underneath the top layer that were undetectable by XPS, semiqualitative STEM energy dispersive X-ray spectroscopy (EDX) was used to confirm that these underlying deposits were both $\mathrm{Fe}$ - and S-rich. Selected area electron diffraction patterns were collected using a transmission electron microscope (TEM) [JEOL 2010 $\mathrm{LaB}_{6}$, JEOL Ltd.] to further confirm the structure of the deposits. Electron diffraction patterns were collected along three separate zone axes, one primary and two secondary zones. The collected patterns were then compared to simulated patterns for several iron sulfide crystal structures, stoichiometries and variants thereof, including cubic FeS, greigite, mackinawite and hexagonal pyrrohotite. These patterns were simulated using 
the CrystalMaker software suite equipped with Single Crystal 2. Once the correct variant was detected, its lattice constants were refined ( $<5 \%$ from original) until an exact match was achieved along all three zone axes.

\section{RESULTS}

\section{A. Structure and thermochemical properties of the model asphaltene}

The purity of BPH was found to be greater than $99 \%$ and its calculated structure is shown in the inset of Fig. 3 (a). The ${ }^{1} \mathrm{H}$ and ${ }^{13} \mathrm{C}$ NMR spectra used to deduce the structure of $\mathrm{BPH}$ are as follows:

${ }^{1} \mathrm{H} \mathrm{NMR}\left(\mathrm{CDCl}_{3}, 400 \mathrm{MHz}\right) \partial 8.67(\mathrm{~d}, J=9.3 \mathrm{~Hz}), 8.19(\mathrm{~d}, J=7.3 \mathrm{~Hz}, 4 \mathrm{H}), 8.12(\mathrm{~d}, J=9.3$ $\mathrm{Hz}, 2 \mathrm{H}$ ), 8.08 (s, 4H), 8.08-7.99 (m, 6H), 3.07 (app. t, $\left.J=7.0 \mathrm{~Hz}, \mathrm{C}_{2}-\mathrm{Ar}, 4 \mathrm{H}\right), 1.66(\mathrm{~m}$, $\left.\mathrm{CH}_{2}-\mathrm{CH}_{2}-\mathrm{Ar}, 4 \mathrm{H}\right), 1.50-1.42\left(\mathrm{~m}, \mathrm{CH}_{2}-\mathrm{CH}_{2}-\mathrm{CH}_{2}-\mathrm{Ar}, 4 \mathrm{H}\right) \mathrm{ppm}$.

${ }^{13} \mathrm{C}$ NMR $\left(\mathrm{CDCl}_{3}, 101 \mathrm{MHz}\right) \partial$ 131.4, 130.9, 129.7, 129.4, 129.1, 127.9, 127.3, 127.0 $126.3,125.6,125.3,125.2,125.1,124.9,124.4,124.2,35.2,29.2,28.3$ ppm.

After the purity and structure of BPH were verified, its physical transformations and thermal decomposition behavior was studied. This was done to help correlate the intrinsic thermochemical behavior of BPH to the deposits formed during fouling. The results of the TGA and DSC tests are shown in Fig. 3 (a) and Fig. 3 (b) respectively. The TGA data for $\mathrm{BPH}$ showed two mass loss events. The first one centered at $134.6^{\circ} \mathrm{C}$ with a mass loss of $0.9 \%$, and the second one centered at $388.1^{\circ} \mathrm{C}$ with a mass loss of $91.5 \%$. The DSC data showed an exothermic peak centered at $75.8^{\circ} \mathrm{C}$ and an endothermic peak centered at $129.2^{\circ} \mathrm{C}$. The first peak is attributed to crystallization of BPH and the second one to its melting. 

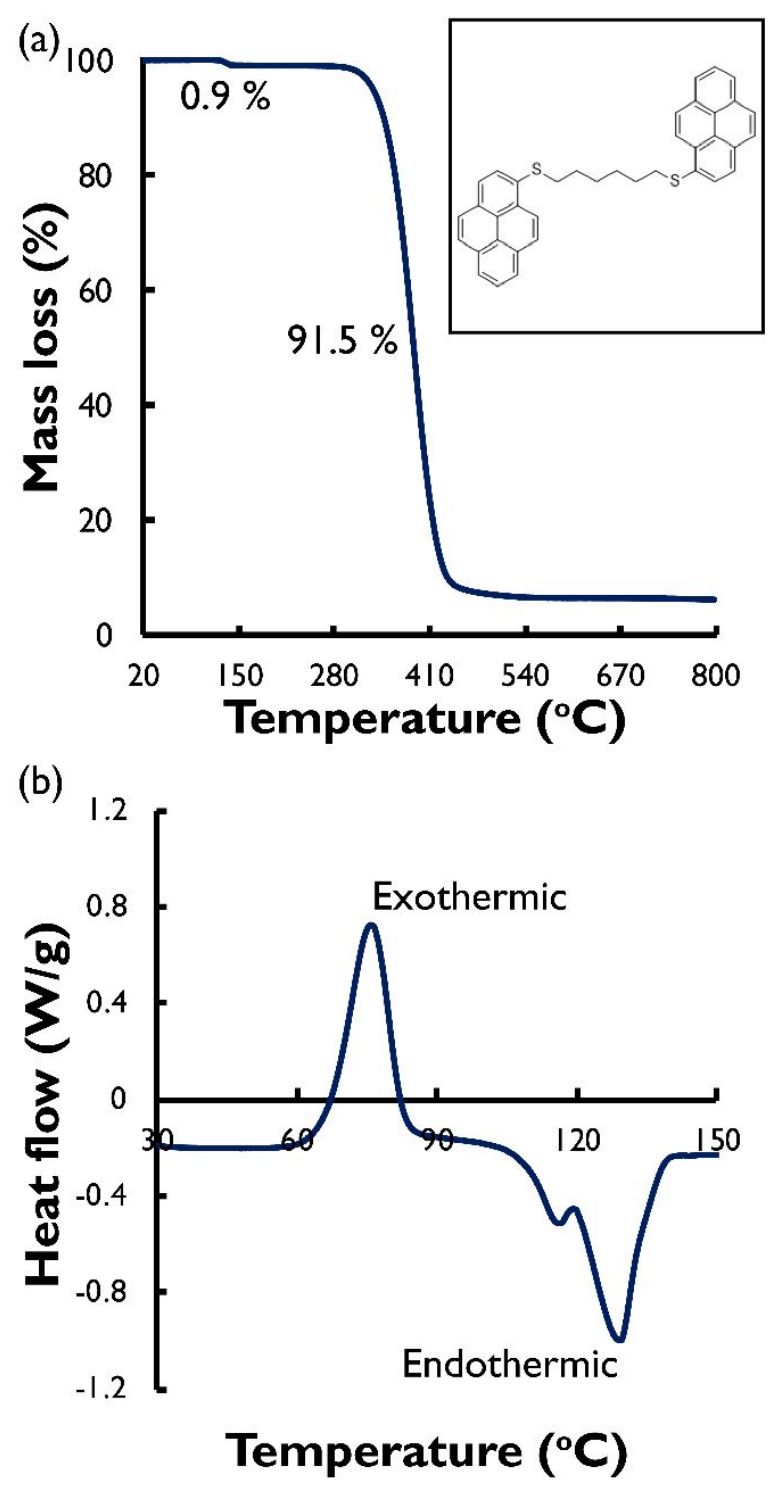

Fig. 3: (a) Thermogravimetric analysis (TGA) data for 1,6-bis(pyren-1-ylthio)hexane shown in the inset, and (b) differential scanning calorimetry (DSC) data for the same model asphaltene. The TGA data showed two mass loss events, the first centered at $134.6^{\circ} \mathrm{C}$ and the second centered at $388.1^{\circ} \mathrm{C}$. The DSC data showed an exothermic peak at $75.8^{\circ} \mathrm{C}$ indicating a crystallization event, and an endothermic peak at $129.2^{\circ} \mathrm{C}$ indicating melting. 


\section{B. Surface characterization of unpassivated and passivated samples}

In order to understand the reaction mechanisms that lead to deposit formation during fouling, it is important to have a thorough characterization of both the foulant and the surface being fouled. Thus, XPS characterization of a smooth unpassivated X65 substrate before fouling is shown in Fig. 4 (a). Fitting the core level Fe $2 p_{3 / 2}$ line, the surface oxide was found to be $\mathrm{Fe}_{2} \mathrm{O}_{3} \cdot{ }^{37}$ However, some $\mathrm{Fe}$ signal was also present indicating that the native oxide is thin or discontinuous and photoelectrons from the steel can reach the detector. ${ }^{38}$ Fitting the core level AI $2 p$ line, the surface oxide of an ALD alumina passivated $\mathrm{X} 65$ surface showed primarily $\mathrm{Al}_{2} \mathrm{O}_{3}$ with some aluminum hydroxide on the surface as shown in Fig. 4 (b). ${ }^{25}$ No Fe signal was observed for the alumina passivated X65 samples. As expected, all samples tested by XPS showed adventitious carbon in the $\mathrm{C}-\mathrm{C}, \mathrm{C}-\mathrm{O}-\mathrm{C}$, and $\mathrm{O}-\mathrm{C}=\mathrm{O}$ states on the surface (not shown).

To allow the correlation between surface features and deposit morphology, monolayer IOs of the target diameters stated in Section II. B. were successfully fabricated and passivated with ALD alumina. A representative $250 \mathrm{~nm}$ rough $\mathrm{IO}$ that was passivated with ALD alumina is shown in Fig. 5 (a)-(b). The IOs were found to be uniform over millimeter length scales. Additionally, despite the high surface area and porosity of the IOs, the ALD alumina coating was found to be conformal. 

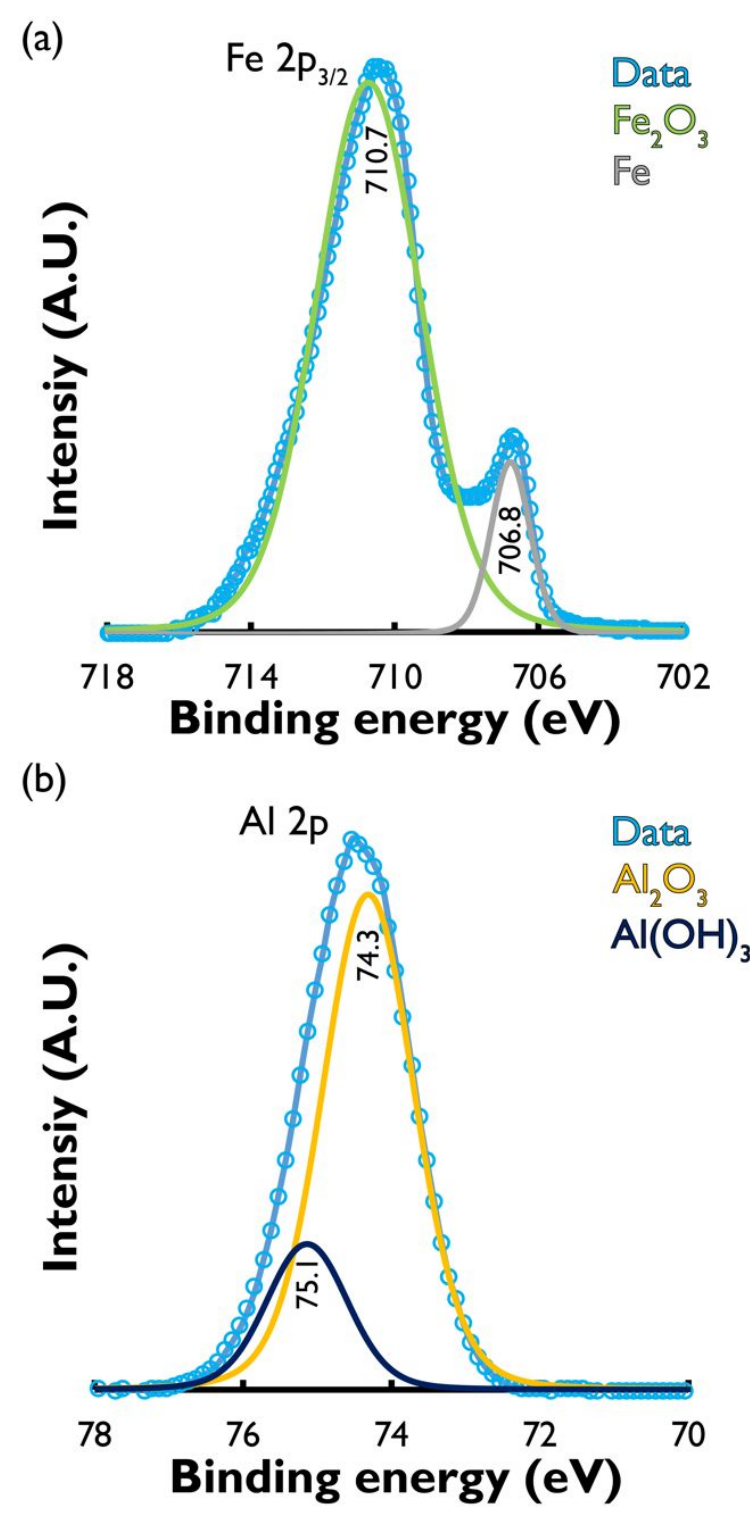

Fig. 4: X-ray photoelectron spectroscopy data for (a) polished and cleaned X65 substrate, and (b) polished and cleaned $30 \mathrm{~nm}$ thick atomic layer deposition (ALD) alumina coated X65 substrate. Using the $\mathrm{Fe} 2 p_{3 / 2}$ line, the surface chemistry of the X65 substrate was found to be a majority of $\mathrm{Fe}_{2} \mathrm{O}_{3}$ with $\mathrm{Fe}$ signal from the substrate. The surface chemistry of the ALD alumina coated $X 65$ substrate was found to be $\mathrm{Al}_{2} \mathrm{O}_{3}$ with some aluminum hydroxide using the $A / 2 p$ line. 


\section{HPHT fouling results and deposit characterization}

After characterizing the intrinsic behavior of BPH and the surface chemistry of the substrates, HPHT fouling tests were conducted. Area normalized mass gain results of the HPHT fouling tests are shown in Fig. 6. The mass gain for the unpassivated X65 substrates at $350^{\circ} \mathrm{C}$ showed a strong correlation with surface roughness. However, the dependence on surface roughness was weak at the lower fouling temperature. In contrast, the ALD alumina passivated X65 substrates showed a weak correlation with roughness at both $150{ }^{\circ} \mathrm{C}$ and $350{ }^{\circ} \mathrm{C}$. The total amount of deposition at both temperatures was lower for the passivated surface. The difference in mass gain between the passivated and unpassivated substrates was significantly larger at $350{ }^{\circ} \mathrm{C}$. Such quantification was not possible for the IOs because localized delamination of the IOs from the substrate convoluted the interpretation of mass change measurements. 


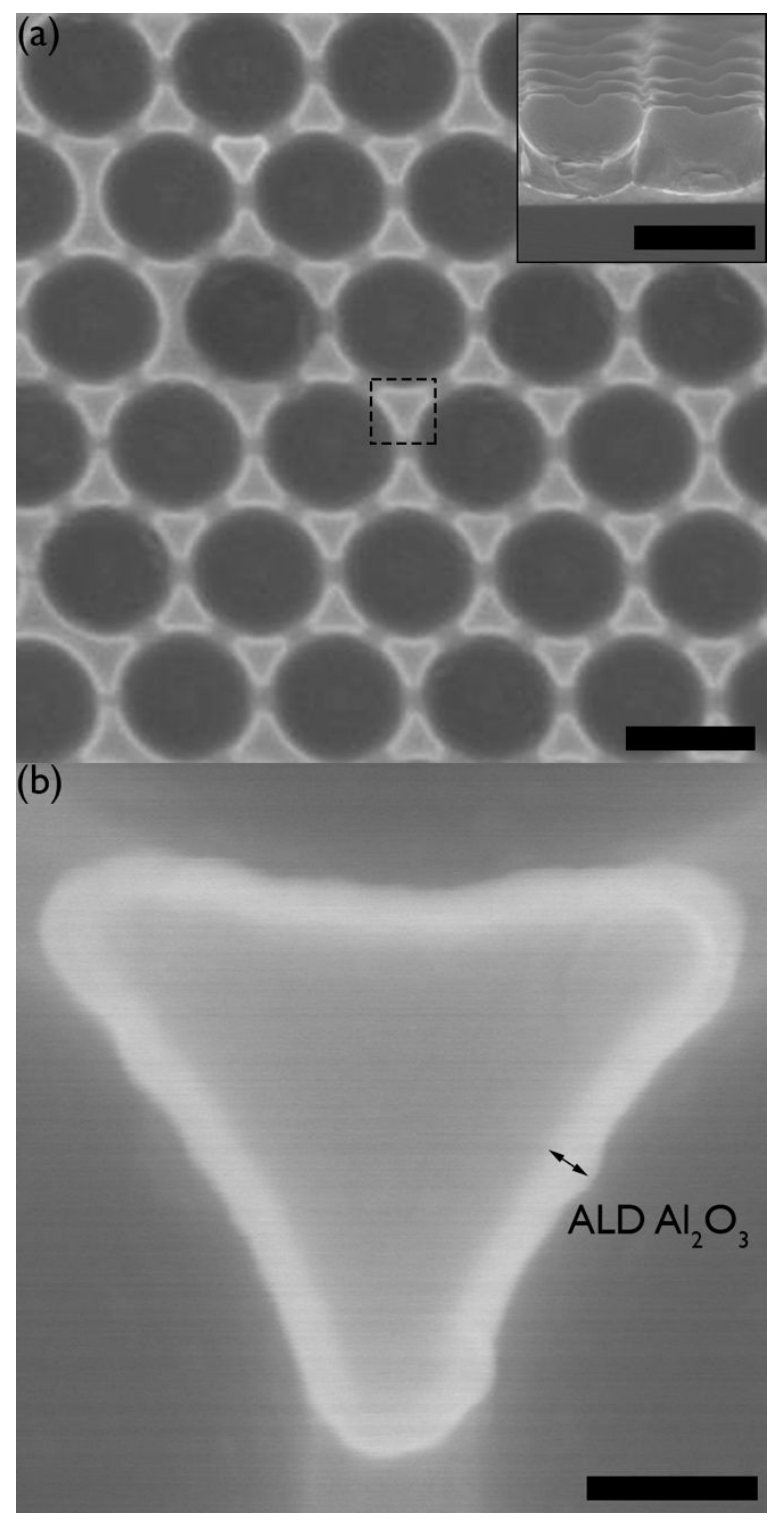

Fig. 5: Scanning electron micrographs of atomic layer deposition (ALD) alumina coated on a $250 \mathrm{~nm}$ rough inverse opal (IO) template. (a) Plan view and section view (inset) of the as-deposited IOs. The scale bar is $500 \mathrm{~nm}$ for both (a) and its inset. (b) High magnification image of a strut as demarcated by a dashed square in (a) showing the conformal ALD alumina coating. The scale bar for (b) is $100 \mathrm{~nm}$. The deterministic geometry of the surface allows for easier correlation between surface roughness and deposit morphology. 
At $150{ }^{\circ} \mathrm{C}$, platelet deposits were observed on the passivated $\mathrm{X} 65$ substrates as well as the IOs of different diameters as shown in Fig. 7 (a)-(h). For the passivated X65 substrate, the deposits stem off each other at several inclination angles, and sizes as shown in Fig. 7 (a) and (e). It is not straightforward to correlate the deposit size to specific surface features. However, in the case of the IOs, a positive correlation between the pore size and the size of the deposits was observed.

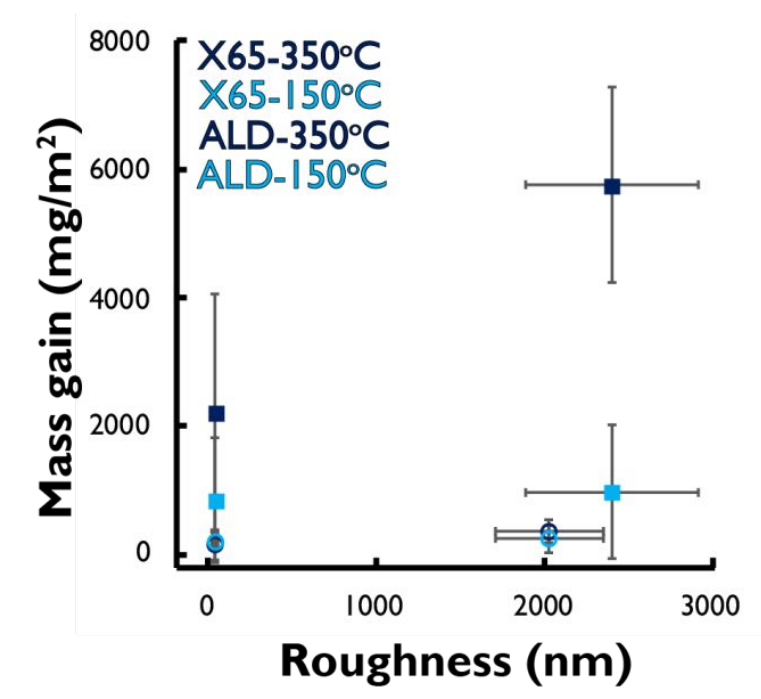

Fig. 6: High pressure and high temperature fouling mass gain results for unpassivated and atomic layer deposition (ALD) alumina passivated X65 substrates. The dark blue squares represent unpassivated $X 65$ substrates fouled at $350^{\circ} \mathrm{C}$, the light blue squares represent unpassivated $X 65$ substrates fouled at $150^{\circ} \mathrm{C}$, the dark blue circles represent ALD alumina passivated $X 65$ substrates fouled at $350{ }^{\circ} \mathrm{C}$, and the light blue circles represent $A L D$ alumina passivated $X 65$ substrates fouled at $150^{\circ} \mathrm{C}$. The total mass gain and its dependence on roughness was drastically reduced for the ALD passivated substrates.

At $350^{\circ} \mathrm{C}$, where $\mathrm{BPH}$ is at least partially decomposed, the deposit morphology for passivated and unpassivated X65 substrates is shown in Fig. 8 (a)-(e). The deposits on the rough, unpassivated surfaces (cf Fig. 8 (c)) were large and bulbous compared to the smaller deposits (cf Fig. 8 (a)-(b)) on the smooth surfaces. In stark contrast to this, the ALD alumina passivated X65 substrates showed very few deposits and the SEM micrographs (cf Fig. 8 (d)-(e)) of the surfaces show the stochastic roughness of the 
substrate. A more detailed comparison of the surface morphology of the fouled smooth surfaces (cf Fig. 8 (a) and Fig. 8 (d)) can be found in Fig. 9 (a)-(b).

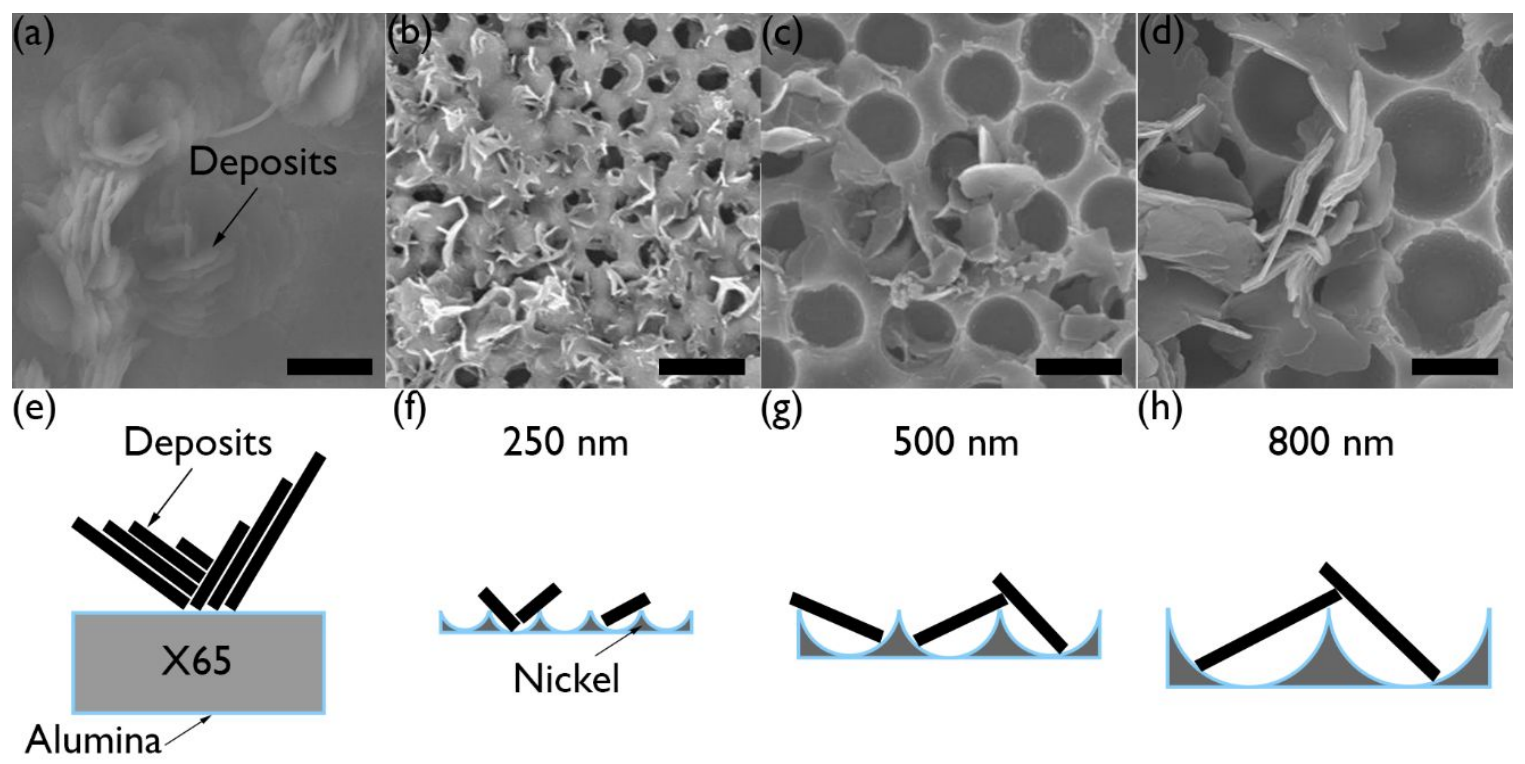

Fig. 7: Scanning electron micrographs of (a) smooth X65 steel, (b) $250 \mathrm{~nm}$ rough inverse opal (IO), (c) $500 \mathrm{~nm}$ rough IO, and (d) $800 \mathrm{~nm}$ rough IO. All samples were passivated with atomic layer deposition alumina to reduce thermal creep and fouled at $150^{\circ} \mathrm{C}$. The schematics shown in parts (e) through (f) illustrate the proposed mechanism to explain the observed correlation between deposit size and surface roughness in parts (a) through (d) respectively. Rougher IOs allow for larger deposits due to increased distance between physical barriers to deposit growth. The scale bar for (a) is $5 \mu \mathrm{m}$. All other scale bars are $2 \mu m$.

The specimens shown in Figure 8 (d)-(e) were coated with $30 \mathrm{~nm}$ of ALD alumina. A range of coating thicknesses were investigated $(0.5 \mathrm{~nm}$ to $30 \mathrm{~nm})$. No significant foulant build-up was observed on ALD alumina passivated surfaces with coatings greater than $5 \mathrm{~nm}$. Below a passivation thickness of $5 \mathrm{~nm}$, a mixed mode of deposition was observed with deposits only growing on certain regions of the sample. Below $3.5 \mathrm{~nm}$ of ALD alumina coating, the samples were uniformly covered in deposits similar to the unpassivated X65 substrates. A box plot depicting the mass gain results for varying ALD alumina growth cycles ( 1 cycle $\sim 0.1 \mathrm{~nm}$ ) is shown in Fig. 10. Corresponding optical images of the fouled 
surface of representative samples from each of the three types of deposition regimes are also provided.

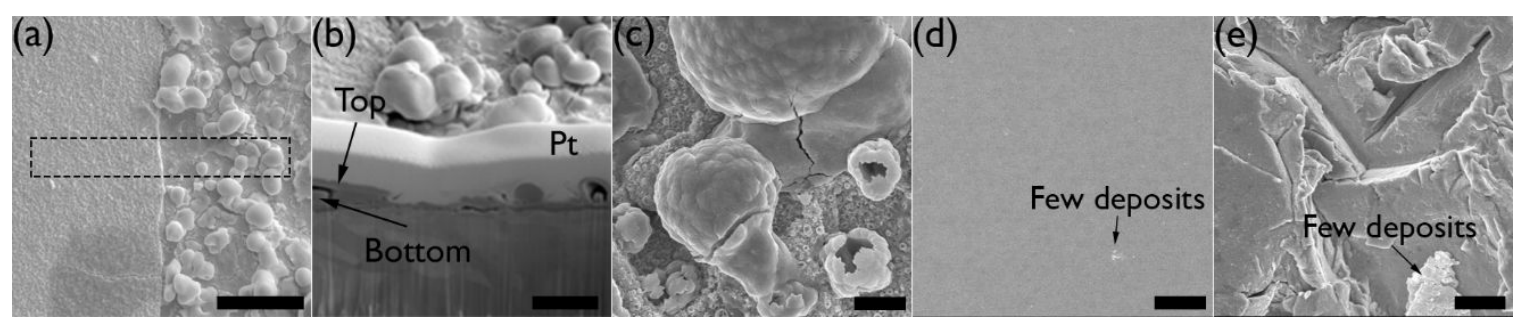

Fig. 8: Scanning electron micrographs of (a) smooth and (c) rough unpassivated X65 steel; (d) smooth and (e) rough atomic layer deposition alumina passivated X65 steel after fouling at $350^{\circ} \mathrm{C}$. The image in (a) shows the intersection between a delaminated and intact top deposit layer with a cross-section from the region demarcated with the dashed rectangle shown in (b). Larger, and more numerous deposits were found for the rough surfaces in comparison to the smooth surfaces with the same surface chemistry. The deposits in (a) were bi-layered. The protective focused ion beam platinum layer is labeled as Pt. The scale bar is $5 \mu \mathrm{m}$ for (a), (c), (d) and (e). The scale bar for (b) is $2 \mu \mathrm{m}$.

Morphological descriptions of the deposits formed at $350^{\circ} \mathrm{C}$ are complemented by more thorough chemical characterization. Baseline surface chemistry was established by characterizing the surface chemistry of an unpassivated X65 coupon dipped in the surrogate fuel at room temperature. The $S 2 p$ core line for this baseline sample identified free BPH on the surface with similar bonding characteristics as a thiol group (cf Fig. 11 $(a)), S 2 p_{3 / 2}$ binding energy (B.E.) $=163.5 \mathrm{eV}$ ). ${ }^{39}$ The $S 2 p$ core line had identical peak positions for an ALD passivated X65 substrate as well, this supports the idea that BPH merely remains physisorbed to the surface. 

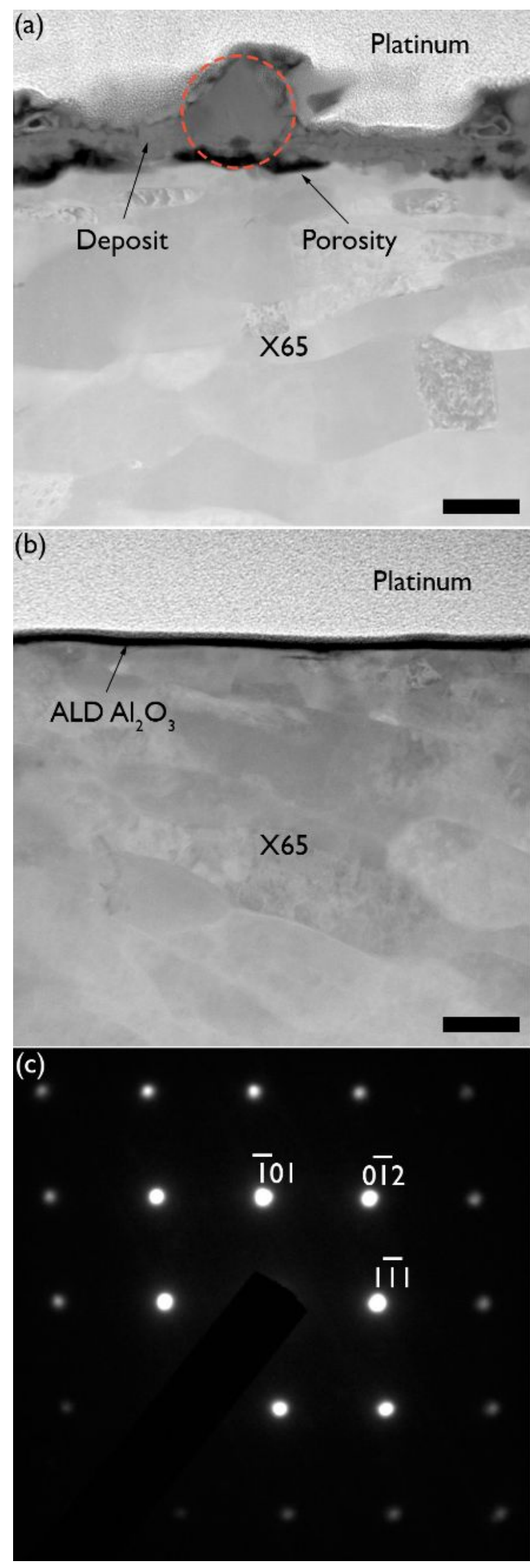
Fig. 9: Scanning transmission electron micrographs of (a) smooth unpassivated X65 steel, and (b) smooth atomic layer deposition (ALD) alumina passivated X65 steel after fouling at $350^{\circ} \mathrm{C}$. The sample in (a) was lifted out from a region where the top deposit layer was delaminated. A mixed deposit was observed in (a) with both "mat" and faceted regions. The deposits were weakly adhered to the surface as evidenced by several instances of surface porosity. No discernable deposits were seen in the ALD alumina passivated X65 substrate even with as low as a $5 \mathrm{~nm}$ thick passivation layer. The scale bars are $200 \mathrm{~nm}$. Part (c) is a selected area electron diffraction pattern of the faceted deposit demarcated with a dashed circle in (a) along the [121] zone. The deposit is identified as hexagonal pyrrhotite $\left(\mathrm{Fe}_{1-\mathrm{x}} \mathrm{S}\right)$.

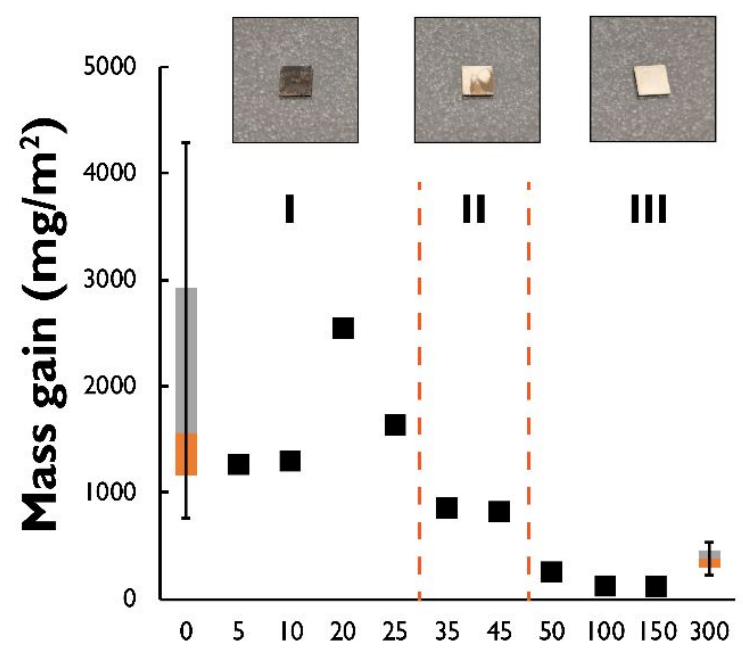

Alumina growth cycles (\#)

Fig. 10: Box plot comparing the mass gain of atomic layer deposition alumina coated X65 substrates for different coating thicknesses. Three deposition regimes were identified: I) complete deposit coverage, II) partial deposit coverage, and III) full passivation where little deposition was observed. These regions correspond to coating thicknesses of 0 to $3.5 \mathrm{~nm}, 3.5$ to $5 \mathrm{~nm}$, and greater than $5 \mathrm{~nm}$ respectively. Digital images of representative samples from each of the three regions is also provided.

The results of XPS characterization of the deposits formed on the unpassivated and passivated $\mathrm{X} 65$ substrates at $350{ }^{\circ} \mathrm{C}$ is shown in Fig. 11 (b) and Fig. 11 (c) respectively. Compared to the baseline, a peak was detected at a B.E. of $163 \mathrm{eV}$ for the unpassivated $\mathrm{X} 65$ substrate fouled at $350{ }^{\circ} \mathrm{C}$, thus revealing the presence of a thiolate Shetty, et al. Surface chemistry, roughness \& high temperature deposition asphaltenes 
group ( $M-S_{\text {thiolate, }}$ where $M$ stands for a metal center). ${ }^{39,40}$ The thiolate group is identified as $\mathrm{Fe}-\mathrm{S}_{\text {thiolate }}$ since $\mathrm{Fe}$ was the only metallic species at the surface. Additionally, a peak was also identified at a B.E. of $161.8 \mathrm{eV}$, this indicated the presence of a sulfide. The sulfide group is identified as $\mathrm{Fe}_{1-x} \mathrm{~S} .{ }^{41}$ Similarly, analyzing the $S 2 p$ core line revealed the presence of a metal sulfate at the surface of the ALD alumina passivated X65 substrate $(\mathrm{S} 2 \mathrm{p} \mathrm{B.E.}=169.2 \mathrm{eV}) .{ }^{42}$ The metal sulfate is identified as aluminum sulfate since Al was the only metallic species at the surface.

Since the deposits formed at $350^{\circ} \mathrm{C}$ on the unpassivated $\mathrm{X} 65$ substrates were bilayered (cf Fig. 8 (b)), it is apparent that XPS could not resolve the chemistry of the distinct layers of deposits. Under the top "mat" layer, there was evidence of gas pockets and faceted deposits. Thus a complementary electron diffraction technique was required to discern the chemistry of the faceted bottom layer deposits. Using electron diffraction in the TEM, the faceted deposits formed on unpassivated $\mathrm{X} 65$ at $350^{\circ} \mathrm{C}$ were identified as hexagonal pyrrhotite $\left(\mathrm{Fe}_{1-\mathrm{x}} \mathrm{S}\right)$ as shown in Fig. 9 (c). Thus assimilating the XPS and electron diffraction data, the top layer of deposits must be $\mathrm{Fe}-\mathrm{S}_{\text {thiolate }}$.
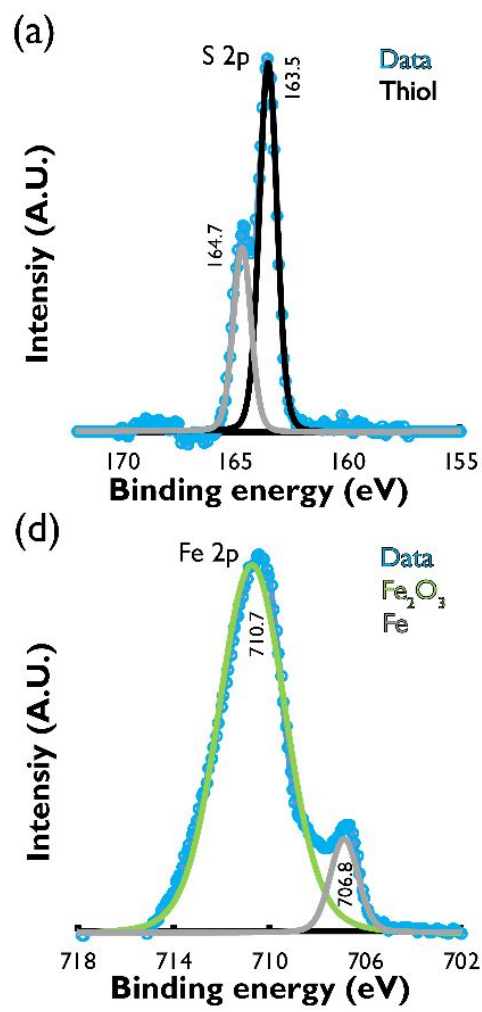

(b)

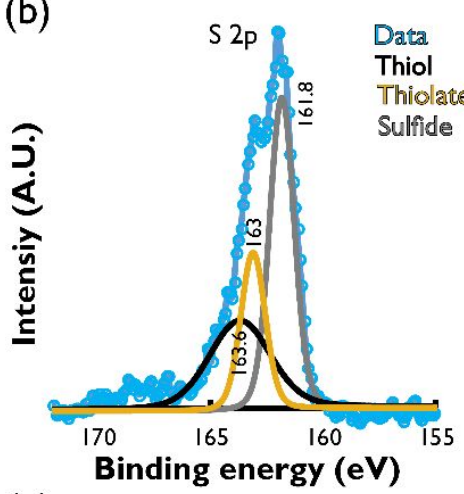

(e)

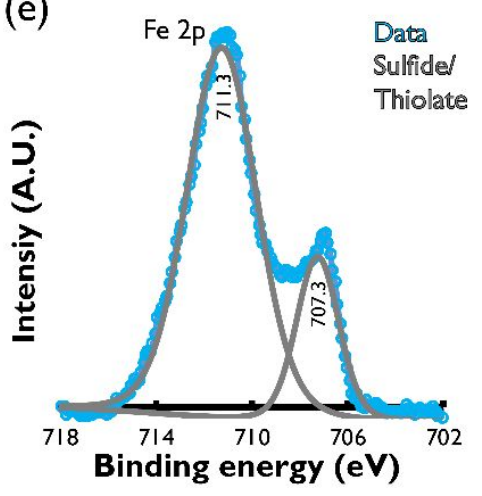

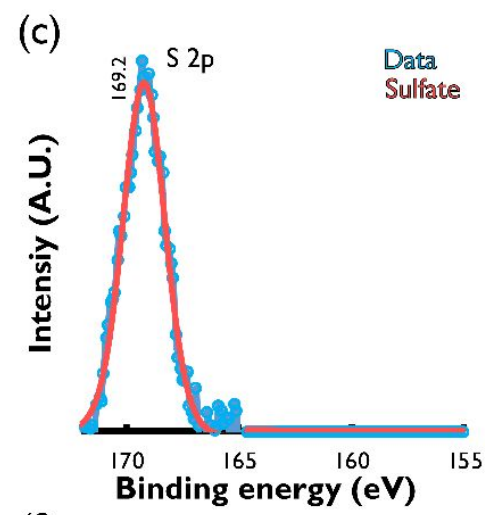

(f)

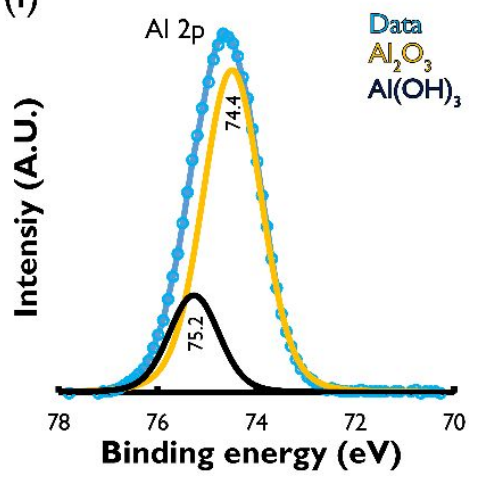


Fig. 11: X-ray photoelectron spectroscopy (XPS) data for $S 2 p$ core levels from (a) an unpassivated $X 65$ dipped in the surrogate fuel at room temperature, (b) fouled unpassivated X65 substrate, and (c) fouled atomic layer deposition (ALD) alumina passivated X65 substrate. The fouling temperature used for $(b)$ and (c) was $350^{\circ} \mathrm{C}$. The corresponding Fe $2 p$, Fe $2 p$, and Al $2 p$ core levels for the samples in parts (a), (b), and (c) are shown in parts (d), (e), and (f) respectively. The surface in (a) contained a thiol group in an unbound state and oxidized sulfur species (B.E. $=164.7 \mathrm{eV})$. The surface in (b) was found to contain a thiolate and sulfide in addition to the unbound thiol. The shift in the Fe 2p B.E. in part (e) compared to the unfouled state (cf Fig. 4 (a)) further supports the finding of a surface thiolate and sulfide. The surface in (c) was found to contain a metal sulfate. The spectra in parts (d) and (f) closely resemble the XPS data collected for the corresponding unfouled surfaces shown in Fig. 4, this indicates that the deposits on these surfaces are very thin.

\section{DISCUSSION}

A fouling resistant surface would ideally remain unchanged or realistically change slowly and predictably after exposure to asphaltenes at high temperatures. The following sections aim to contextualize the presented data, thereby establishing fundamental connections between the thermochemistry of the model asphaltene, deposit morphology and chemistry, and different surface preparations. These connections may ultimately be useful in realizing the goal of predictable surface evolution in traditional fouling environments.

\section{A. Fouling temperature and thermochemical stability}

The DSC data (cf Fig. 3 (b)) suggest that BPH undergoes an amorphous to crystalline physical transformation at $75.8^{\circ} \mathrm{C}$. Though the crystallization behavior of dilute $\mathrm{BPH}$ in the surrogate fuel is expected to be different than pure $\mathrm{BPH}$ in $\mathrm{N}_{2}$, evidence of crystallization can be seen from the nature of deposits formed at $150^{\circ} \mathrm{C}$ (cf Fig. 7) during the HPHT fouling tests. We initially posited that crystallization of BPH would be favored because of strong $\pi-\pi$ interactions between the pyrene residues. ${ }^{43}$ However, analysis of the crystal structure of BPH (see Fig. S1 (a) in the Supplementary Information) indicates that the crystal packing in this case is dominated by $\mathrm{CH}-\pi$ interactions between adjacent 
molecules such that the mean planes containing adjacent pyrene rings have a tilt angle of $59.47^{\circ}$ (see Fig. S1 (b) in the Supplementary Information).

Centered at $350^{\circ} \mathrm{C}$, the large mass loss in the TGA data (cf Fig. 3 (a)) suggests that BPH undergoes a thermal decomposition. Similar decomposition has been reported for extracted asphaltenes in the temperature range of 300-500 ${ }^{\circ} \mathrm{C}$ in both air and $\mathrm{N}_{2}$ environments. ${ }^{44,45}$ However, the rapid mass loss region in the TGA data is usually less abrupt than in the case of BPH and shows a more gradual decrease. This is attributed to the chemical inhomogeneity of extracted asphaltenes compared to a model isolated asphaltene like $\mathrm{BPH}$. Unlike the isolated model asphaltene used in this study, extracted asphaltenes would comprise of a very large variety of asphaltene molecules. Since each type of molecule would have its own distinct decomposition temperature and set of decomposition products, the number of possible deposits would also be large and consequently difficult to characterize. The use of a model asphaltene helps circumvent these complexities and allows for a more direct correlation between the thermochemical properties of the asphaltene and the resulting deposits.

Since BPH contains a significantly higher $S$ content compared to extracted asphaltenes, its decomposition behavior is compared to organosulfur compounds instead. Previous studies have also reported the thermal decomposition of organosulfur compounds at elevated temperatures. ${ }^{46,47}$ Specifically, Thompson, Meyer and Ball ${ }^{47}$ proposed three principal reaction products in the decomposition for 2-methyl-2propanethiol: elemental sulfur, $\mathrm{H}_{2} \mathrm{~S}$ gas, and gaseous hydrocarbons. The mechanism for the formation of these decomposition products was proposed to be a free radical chain type. Inspection of standard bond dissociation energies ${ }^{48}$ for the functionality present in $\mathrm{BPH}$ suggests that homolysis would occur at the weaker alkyl C-S bonds. This assumption is further substantiated by the work of Fine and Westmore ${ }^{49}$ and it follows therefore that thiyl radicals, Pyr-S- (Pyr stands for pyrene), would be generated after thermal decomposition of BPH. ${ }^{50}$ In the context of the HPHT experimental conditions, this thermochemical description of the model asphaltene molecule can be used to better understand the reaction pathways at the asphaltene-metal interface. 


\section{B. Deposit morphology and surface roughness}

Surface roughness is considered to be an important factor in the inhibition of various forms of fouling and corrosion. ${ }^{51,52}$ In fact, improving the surface finish to reduce deposition has been widely used in the oil and gas industry.11,12 However, the mechanisms underlying this empirical knowledge are poorly understood. For example, $\mathrm{HPHT}$ experiments conducted at $150^{\circ} \mathrm{C}$, where $\mathrm{BPH}$ remains thermally stable and does not generate reactive products, results in deposition behavior that is dominated by surface morphology/roughness rather than surface chemistry. This reduced dependence on surface chemistry is apparent when comparing the difference in mass gain between the passivated and unpassivated steel (cf Fig. 6) at $150^{\circ} \mathrm{C}$.

Indeed rough surfaces can provide more physical entrapment sites for foulants in hydrodynamic environments. However, the mass gain data in this study were collected in a static environment and roughness still seems to play a significant role for unpassivated surfaces. Another postulate is that the greater surface area of the rough surfaces provides more nucleation sites for deposition to initiate. According to the data presented in Fig. 6, the increase in area from the smooth to rough surface was calculated to be $13.2 \%$ using Eq. 1. And the corresponding increase in mass gain was $16.3 \%$ for the unpassivated $\mathrm{X} 65$ at $150^{\circ} \mathrm{C}$. Though these values are comparable, they do not provide any information about the size distribution of the deposits.

Comparing the size of deposits between smooth and rough surfaces of the same chemistry (cf Fig. 7 (b)-(d) and Fig. 8 (a) and (c)), the deposits are noticeably larger on the rough surfaces. Based on these observations, a mechanism is proposed to explain the effect of roughness on asphaltene deposition. In addition to the additional entrapment sites, and increased surface area, rough surfaces display larger deposits due to increased distance between to deposit growth. Assuming the same deposit chemistry, temperature can further exacerbate this effect since the kinetics of deposit growth will be faster at higher temperatures. A schematic displaying this mechanism is shown in Fig. 7 (f)-(h). The use of a model asphaltene on a model deterministic surface helps to directly correlate deposit size with the characteristic feature size on the surface. However, careful inspection of the smooth ALD coated X65 substrate fouled at $150{ }^{\circ} \mathrm{C}$ (cf Fig. 7 (a) and 
(e)) shows that deposits do not always nucleate at the surface, rather they can begin to stem off each other. As a result, both the structure and chemistry of the surface evolves and, as it does so, it may dramatically alter the mode of asphaltene deposition (cf Fig. 8 (a) versus $(d)$ ).

\section{Surface chemistry and deposit chemistry}

Regardless of the surface finish, even localized regions of reactive surface chemistry may lead to uncontrolled fouling and corrosion. This is especially true at high temperatures where organosulfur compounds begin to decompose into reactive products as mentioned in Section IV. A. In the case of the unpassivated X65 steel, a bi-layered deposit with two different chemistries was identified in Section III. C. The top mat layer was identified as a Fe-S thiolate species using XPS (cf Fig. 11 (b)). This is consistent with the hypothesis that Pyr-S• free radicals were present at $350^{\circ} \mathrm{C}$. Thus the top mat layer is proposed to have a Fe-S-Pyr chemistry.

Iron thiolates have been shown to be stable (interactive binding energy $\sim-564.8$ $\mathrm{kJ} / \mathrm{mol}$ ) using time dependent density functional theory calculations. ${ }^{53}$ The bonding between the Fe center and thiolate group is proposed to be a co-ordinate covalent bond which may have a strong covalent nature. However, before fouling, the surface chemistry for the unpassivated $\mathrm{X} 65$ was confirmed to be $\mathrm{Fe}_{2} \mathrm{O}_{3}$ using XPS (cf Fig. 4 (a)). Thus, in order for Fe-S-Pyr to form, a Fe-O bond (bond dissociation energy (B.D.E.) $=409 \pm 13$ $\mathrm{kJ} / \mathrm{mol})^{48}$ would have to dissociate. Iron may also be present at the surface because of discontinuities in the native oxide and/or diffusion of Fe through the native oxide. Such free Fe atoms could also provide bonding sites for the thiyl free radicals to form thiolate species at the surface.

Furthermore, under the mat deposit, faceted $\mathrm{Fe}_{1-\mathrm{x}} \mathrm{S}$ (pyrrhotite) deposits were identified on unpassivated substrates at $350^{\circ} \mathrm{C}$ using electron diffraction (cf Fig. 9 (a) and (c)). Other studies have reported the formation of pyrrhotite on steels in the presence of organosulfur compounds at temperatures above $250{ }^{\circ} \mathrm{C} .{ }^{54}$ The presence of elemental sulfur from the decomposition of BPH could help explain the formation of these bottom layer deposits. However, another more likely mechanism for its formation is the 
decomposition of Fe-S-Pyr to iron sulfide ${ }^{55}$ and other gaseous products, which would further explain the presence of gas pockets in the deposit (cf Fig. 8 (b) and (c)). This mechanism is supported by the observation of faceted deposits encapsulated within hollow outer shells as seen in Fig. 8 (b).

The ALD alumina coated substrates, on the other hand, displayed a controlled fouling behavior with a single deposit chemistry and low mass gain. The continuous, dense film (for thicknesses greater than $5 \mathrm{~nm}$ ) and the stronger Al-O bond (B.D.E. $=512$ $\pm 4 \mathrm{~kJ} / \mathrm{mol})^{48}$ may explain why a similar thiolate species do not form on the ALD passivated X65 substrate. Consequently the thiolate does not dissociate to form aluminum sulfide at the surface. Instead XPS and STEM data identified a thin aluminum sulfate at the surface (cf Fig. 9 (b) and Fig. 11 (c) and (f)).

Previously alumina has been reported to react with $\mathrm{SO}_{2}$ gas to form aluminum sulfate. ${ }^{56}$ However, this is a self-limiting reaction mechanism where $\mathrm{SO}_{2}$ is first chemisorbed on the surface. The chemisorbed $\mathrm{SO}_{2}$ forms a surface aluminum sulfite chemistry. The aluminum sulfite, in the presence of oxygen and at high temperatures, oxidizes to aluminum sulfate. Since elemental $S$ is a likely decomposition product of BPH and the autoclave used in the HPHT tests was sealed in air, $\mathrm{O}_{2}$ is most likely dissolved in the surrogate fuel. The self-limiting nature of this reaction as well as the limited amount of dissolved $\mathrm{O}_{2}$ in solution helps explain the controlled nature of deposition in the case of ALD passivated X65 substrates. A similar reaction pathway could also take place with $\mathrm{SO}_{2}$ and the aluminum in the hydroxide matrix on the surface (cf Fig. 4b).

The positive association between the alumina surfaces and self-limiting deposit chemistry requires that the entire surface is only alumina (or hydroxylated alumina) - that there are no flaws and no possibility for other metallic species to diffuse through the alumina and contaminate the active surface. The thickness of the passivation layer therefore becomes critically important. Below an ALD alumina coating thickness of 3.5 $\mathrm{nm}$, the fouling behavior of the passivated substrates was similar to that of an unpassivated substrate (cf Fig. 10). This observation is attributed to the discontinuous nature of the coatings that left the X65 substrate exposed to reactive species. Adventitious carbon present on the surface and detected with XPS can act as 
heterogeneous nucleation sites and result in an island type alumina growth. Between 3.5 $\mathrm{nm}$ to $5 \mathrm{~nm}$, only certain regions of the substrate showed deposition. This behavior is attributed to the transition from a discontinuous island morphology to a continuous ALD alumina coating with ultrathin regions, or pinhole-like defects that are susceptible to the diffusion of reactive species through them. ${ }^{57}$ Above $5 \mathrm{~nm}$ of coating thickness, however, full passivation was achieved and the mass gain behavior of samples was very similar because of the inert, continuous, and robust nature of the coating.

\section{CONCLUSIONS}

This study provides key insights on the interplay between the thermochemical properties of asphaltenes, environmental conditions, and surface variables that dictate asphaltene deposition. A model sulfur containing archipelago asphaltene was shown to crystallize at intermediate temperatures forming platelet deposits. The size of the platelets corresponded well with the characteristic pore size on deterministic surfaces lending credence to the concept of physical barriers controlling the deposit size. Above $300{ }^{\circ} \mathrm{C}$, the model asphaltene was shown to decompose. The decomposition products are most likely highly reactive components including thiyl free radicals, elemental sulfur, and other gaseous products. Since the thermal stability of the Fe-O bond is lower than the Al-O bond, the reactivity of the decomposition products was severe on the unpassivated surfaces forming thiolate and pyrrhotite deposits in an uncontrolled manner. On the other hand, the alumina passivated surfaces experienced a self-limiting chemisorption and oxidation reaction forming a thin surface layer of aluminum sulfate. Moreover, the alumina passivated surfaces were immune to the diffusion of corrosive species or the iron from the substrate because of its low diffusivity.

Passivating steel substrates with amorphous alumina showed a dramatic reduction in the mass of adhered deposits at both $150^{\circ} \mathrm{C}$ and $350{ }^{\circ} \mathrm{C}$. The effect of surface roughness on deposition was also dramatically reduced on the passivated surfaces. For the specific system studied in this work, controlling the surface roughness can be an effective method to reduce deposition at intermediate temperatures where the model asphaltene molecules remain intact. However, at higher temperatures where the model asphaltene molecules decompose, the surface chemistry must also be selected with 
consideration for the reactive products present in solution. More generally, asphaltenes present in petroleum can undergo physical and chemical transformations over a range of temperatures, meaning that this strategy of passivating surfaces may be an effective method to inhibit deposition for a larger set of operating conditions. Therefore, through thoughtful development of a model system, fundamental insights have been gained on more general aspects of asphaltene deposition and have important ramifications for the design of anti-fouling petroleum processing units. In case of a more complex asphaltene profile, it is important to bear in mind that careful consideration of the reactive species present in solution will be required in order to choose a suitable surface chemistry that inhibits corrosive reactions with those specific species.

\section{ACKNOWLEDGEMENTS}

The authors wish to thank the Seitz Materials Research Laboratory's shared experimental facilities where most of this research was performed. The authors would also like to thank Prof. Shen J. Dillon at the University of Illinois for access to the microbalance for deposit mass measurement. Many thanks to Ernest P. Northen at the MRL Machine Shop for assistance with the autoclave mount machining. The authors would like to acknowledge the funding and technical support from BP through the BP International Centre for Advanced Materials (BP-ICAM) which made this research possible.

Supporting Information. X-ray structure of model asphaltene. 


\section{REFERENCES}

(1) Wang, J.; Ferguson, A. L. Mesoscale Simulation of Asphaltene Aggregation. J. Phys. Chem. B 2016, 120 (32), 8016-8035.

(2) Buenrostro-Gonzalez, E.; Lira-Galeana, C.; Gil-Villegas, A.; Wu, J. Asphaltene Precipitation in Crude Oils: Theory and Experiments. AlChE J. 2004, 50 (10), 2552-2570.

(3) Rudrake, A. Investigation of Asphaltene-Metal Interactions. 2008, 151.

(4) Sabbah, H.; Morrow, A. L.; Pomerantz, A. E.; Zare, R. N. Evidence for Island Structures as the Dominant Architecture of Asphaltenes. Energy and Fuels 2011, 25 (4), 1597-1604.

(5) Sheremata, J. M.; Gray, M. R.; Dettman, H. D.; McCaffrey, W. C. Quantitative Molecular Representation and Sequential Optimization of Athabasca Asphaltenes. Energy and Fuels 2004, 18 (5), 1377-1384.

(6) Murgich, J.; Abanero, J. A.; Strausz, O. P. Molecular Recognition in Aggregates Formed by Asphaltene and Resin Molecules from the Athabasca Oil Sand. Energy and Fuels 1999, 13 (2), 278-286.

(7) Siskin, M.; Kelemen, S. R.; Eppig, C. P.; Brown, L. D.; Afeworki, M. Asphaltene Molecular Structure and Chemical Influences on the Morphology of Coke Produced in Delayed Coking. Energy and Fuels 2006, 20 (3), 1227-1234.

(8) Pomerantz, A. E.; Wu, Q.; Mullins, O. C.; Zare, R. N. Laser-Based Mass Spectrometric Assessment of Asphaltene Molecular Weight, Molecular Architecture, and Nanoaggregate Number. Energy \& Fuels 2015, 29 (5), 28332842.

(9) Strausz, O. P.; Safarik, I.; Lown, E. M.; Morales-Izquierdo, A. A Critique of Asphaltene Fluorescence Decay and Depolarization-Based Claims about Molecular Weight and Molecular Architecture. Energy and Fuels 2008, 22 (2), 1156-1166. 
(10) Midttun, Ø.; Kallevik, H.; Sjöblom, J.; Kvalheim, O. M. Multivariate Screening Analysis of Water-in-Oil Emulsions in High External Electric Fields as Studied by Means of Dielectric Time Domain Spectroscopy. III. Model Emulsions Containing Asphaltenes and Resins. J. Colloid Interface Sci. 2000, 227 (2), 262-271.

(11) M. A. Greaney, T. Bruno, T. A. Ramanarayanan, I. A. Cody, C. C. ChromiumEnriched Oxide Containing Material and Preoidation Method of Making the Same to Mitigate Corrosion and Fouling Associated with Heat Transfer Components. US 8.465,599 B2, 2013.

(12) M. A. Greaney, T. Bruno, A. E. Cooper, I. A. Cody, C. C. Corrosion Resistant Material for Reduced Fouling, a Heat Transfer Component Having Reduced Fouling and a Method for Reducing Fouling in a Refinery, 2012.

(13) Bilden, D. M.; Jones, V. E. Asphaltene Adsorption Inhibition Treatment. 6,051,535, 1997.

(14) Leotaritis, K. J.; Mansoori, G. A. Asphaltene Deposition: A Survey of Field Experiences and Research Approaches. J. Pet. Sci. Eng. 1988, 1 (3), 229-239.

(15) Zhang, D.; Creek, J.; Jamaluddin, A. J.; Marshall, A. G.; Rodgers, R. P.; Mullins, O. C. Asphaltenes - Problematic but Rich in Potential. Oilf. Rev. 2007, No. June, 22-43.

(16) Santos, O.; Anehamre, J.; Wictor, C.; Tornqvist, A.; Nilsson, M. Minimizing Crude Oil Fouling By Modifying the Surface of Heat Exchangers With a Flexible Ceramic Coating. Int. Conf. Heat Exch. Fouling Clean. 2013, 2013 (Dlc), 79-84.

(17) C. Chun, D. S. Deutsch, V. A. McCray, J. E. F. Alumina Forming Bimetallic Tube for Refinery Process Furnaces and Method of Making and Using. US 8,808,867 B2, 2014.

(18) Wang, W.; Watkinson, A. P. Iron Sulphide and Coke Fouling from Sour Oils: Review and Initial Experiments. Proc. Int. Conf. Heat Exch. Fouling Clean. IX 2011, No. August, 23-30. 
(19) Becker, P.; Young, D. J. Carburization Resistance of Nickel-Base, Heat-Resisting Alloys. Oxid. Met. 2007, 67 (5-6), 267-277.

(20) Kai, W.; Douglass, D. L. The High-Temperature Corrosion Behavior of Fe-Mo-A1 Alloys in $\mathrm{Hz} / \mathrm{HzO} / \mathrm{HzS}$ Mixed-Gas Environments. Corrosion 1993, 39, 281-316.

(21) Cao, X. Q.; Vassen, R.; Stoever, D. Ceramic Materials for Thermal Barrier Coatings. J. Eur. Ceram. Soc. 2004, 24 (1), 1-10.

(22) Clark, E. A.; Yang, J. Y.; Kumar, D.; Was, G. S.; Levi, C. G. Engineered Coatings for Ni Alloys in High Temperature Reactors. Metall. Mater. Trans. A Phys. Metall. Mater. Sci. 2013, 44 (2), 835-847.

(23) Müller, J.; Neuschütz, D. Efficiency of a-Alumina as Diffusion Barrier between Bond Coat and Bulk Material of Gas Turbine Blades. User Model. User-adapt. Interact. 2003, 71 (1-2 SPEC.), 247-251.

(24) Jedlinski, J. The Oxidation Behaviour of FeCrAl 'Alumina Forming' Alloys at High Temperatures. Solid State Ionics 1997, 101, 1033-1040.

(25) Díaz, B.; Härkönen, E.; Światowska, J.; Maurice, V.; Seyeux, A.; Marcus, P.; Ritala, M. Low-Temperature Atomic Layer Deposition of Al2O3thin Coatings for Corrosion Protection of Steel: Surface and Electrochemical Analysis. Corros. Sci. 2011, 53 (6), 2168-2175.

(26) Alboudwarej, H.; Pole, D.; Svrcek, W. Y.; Yarranton, H. W. Adsorption of Asphaltenes on Metals. Ind. Eng. Chem. Res. 2005, 44 (15), 5585-5592.

(27) Stott, F. H.; Hiramatsu, N. Breakdown of Protective Scales during the Oxidation of Thin Foils of Fe-20Cr-5Al Alloys at High Temperatures. Mater. High Temp. 2000, 17 (1), 93-99.

(28) Groner, M. D.; Fabreguette, F. H.; Elam, J. W.; George, S. M. Low-Temperature Al2O3 Atomic Layer Deposition. Chem. Mater. 2004, 16 (4), 639-645.

(29) Zhu, S.; Wang, F.; Lou, H.; Wu, W. Reactive Sputter Deposition of Alumina Films 
on Superalloys and Their High-Temperature Corrosion Resistance. Surf. Coatings Technol. 1995, 71 (1), 9-15.

(30) Golim, O. P.; Prastomo, N.; Synthesized, O. F. Synthesis of Alumina Thin Films Using Reactive Magnetron Sputtering Method. 2017, 6-10.

(31) Adams, J. J. Asphaltene Adsorption, a Literature Review. Energy and Fuels 2014, 28 (5), 2831-2856.

(32) Vicente, L.; Soto, C.; Pacheco-Sánchez, H.; Hernández-Trujillo, J.; MartinezMagadán, J. M. Application of Molecular Simulation to Calculate Miscibility of a Model Asphaltene Molecule. Fluid Phase Equilib. 2006, 239 (1), 100-106.

(33) Moreira Da Costa, L.; Stoyanov, S. R.; Gusarov, S.; Seidl, P. R.; Walkimar De M. Carneiro, J.; Kovalenko, A. Computational Study of the Effect of Dispersion Interactions on the Thermochemistry of Aggregation of Fused Polycyclic Aromatic Hydrocarbons as Model Asphaltene Compounds in Solution. J. Phys. Chem. A 2014, 118 (5), 896-908.

(34) Headen, T. F.; Boek, E. S.; Jackson, G.; Totton, T. S.; Müller, E. A. Simulation of Asphaltene Aggregation through Molecular Dynamics: Insights and Limitations. Energy and Fuels 2017, 31 (2), 1108-1125.

(35) Shetty, P. P.; Zhang, R.; Angle, J. P.; Braun, P. V.; Krogstad, J. A. Pack Aluminization Assisted Enhancement of Thermo-Mechanical Properties in Nickel Inverse Opal Structures. Chem. Mater. 2018, acs.chemmater.7b04988.

(36) Lai, L.; Irene, E. Area Evaluation of Microscopically Rough Surfaces. JVST B 1999, 17 (1), 33-39.

(37) Biesinger, M. C.; Payne, B. P.; Grosvenor, A. P.; Lau, L. W. M.; Gerson, A. R.; Smart, R. S. C. Resolving Surface Chemical States in XPS Analysis of First Row Transition Metals, Oxides and Hydroxides: $\mathrm{Cr}, \mathrm{Mn}, \mathrm{Fe}, \mathrm{Co}$ and Ni. Appl. Surf. Sci. 2011, 257 (7), 2717-2730.

(38) Bhargava, G.; Gouzman, I.; Chun, C. M.; Ramanarayanan, T. A.; Bernasek, S. L. 
Characterization of the "Native" Surface Thin Film on Pure Polycrystalline Iron: A High Resolution XPS and TEM Study. Appl. Surf. Sci. 2007, 253 (9), 4322-4329.

(39) Castner, D. G.; Hinds, K.; Grainger, D. W. X-Ray Photoelectron Spectroscopy Sulfur $2 p$ Study of Organic Thiol and Disulfide Binding Interactions with Gold Surfaces. Langmuir 1996, 12 (21), 5083-5086.

(40) Pirlot, C.; Delhalle, J.; Pireaux, J. J.; Mekhalif, Z. Surface Modification of Polycrystalline Iron Surfaces by N-Dodecanethiol: An XPS Investigation. Surf. Coatings Technol. 2001, 138 (2-3), 166-172.

(41) Panzner, G.; Egert, B. The Bonding State of Sulfur Segregated to a-Iron Surfaces and on Iron Sulfide Surfaces Studied by XPS, AES and ELS. Surf. Sci. 1984, 144 (2-3), 651-664.

(42) Audi, A. A.; Sherwood, P. M. A. Valence-Band x-Ray Photoelectron Spectroscopic Studies of Manganese and Its Oxides Interpreted by Cluster and Band Structure Calculations. Surf. Interface Anal. 2002, 33 (3), 274-282.

(43) Gruber, T.; Seichter, W.; Weber, E. 1-(Methoxymethyl)Pyrene. Acta Crystallogr. Sect. E Struct. Reports Online 2006, 62 (6), 2569-2570.

(44) Trejo, F.; Rana, M. S.; Ancheyta, J. Thermogravimetric Determination of Coke from Asphaltenes, Resins and Sediments and Coking Kinetics of Heavy Crude Asphaltenes. Catal. Today 2010, 150 (3-4), 272-278.

(45) Wu, H.; Kessler, M. R. Asphaltene: Structural Characterization, Molecular Functionalization, and Application as a Low-Cost Filler in Epoxy Composites. RSC Adv. 2015, 5 (31), 24264-24273.

(46) Christopher, N. S. J.; Cotter, J. L.; Knight, G. J.; Wright, W. W. Thermal Degradation of Poly (Phenylene Sulfide ) and Perfluoropoly (Phenylene Sulfide )*. J. Appl. Polym. Sci. 1968, 12, 863-870.

(47) Thompson, C. J.; Meyer, R. A.; Ball, J. S. Thermal Decomposition of Sulfur Compounds. I. 2-Methyl-2-Propanethiol. J. Am. Chem. Soc. 1952, 74 (13), 3284- 
3287.

(48) Darwent, B. Bond Dissociation Energies in Simple Molecules. Natl. Stand. Ref. Data Syst. Natl. Bur. Stand. 1970, 20402 (C), 23-27.

(49) Fine, D. H.; Westmore, J. B. Heats of Formation of Some Alkylthio Radicals. Can. J. Chem. 1970, 48 (3), 395-400.

(50) Taylor, W. F.; Wallace, T. J. Kinetics of Deposit Formation from Hydrocarbons: Effect of Trace Sulfur Compounds. Ind. Eng. Chem. Prod. Res. Dev. 1968, 7 (3), 198-202.

(51) Howell, D.; Behrends, B. A Review of Surface Roughness in Antifouling Coatings Illustrating the Importance of Cutoff Length. Biofouling 2006, 22 (6), 401-410.

(52) Burstein, G. T.; Pistorius, P. C. Surface-Roughness and the Metastable Pitting of Stainless-Steel in Chloride Solutions. Corrosion 1995, 51 (5), 380-385.

(53) Solomon, E. I.; Gorelsky, S. I.; Dey, A. Metal-Thiolate Bonds in Bioinorganic Chemistry. J. Comput. Chem. 2009, 30 (10), 1545-1614.

(54) Pareek, V. K.; Ramanarayanan, T. A.; Mumford, J. D.; Ozekcin, A.; Scanlon, J. C. The Role of Morphology and Structure in the Kinetic Evolution of Iron-Sulfide Films on Fe-Base Alloys. Oxid. Met. 1994, 41 (5-6), 323-341.

(55) Wallace, T. J. Reactions of Thiols with Metals. I. Low-Temperature Oxidation by Metal Oxides. J. Org. Chem. 1966, 31 (4), 1217-1221.

(56) Mitchell, M. B.; Sheinker, V. N.; White, M. G. Adsorption and Reaction of Sulfur Dioxide on Alumina and Sodium-Impregnated Alumina. J. Phys. Chem. 1996, 100 (18), 7550-7557.

(57) S.M. George. Atomic Layer Deposition: An Overview. Chem. Rev. 2010, 110, 111. 


\section{FIGURE CAPTIONS}

Fig. 1: Method used to fabricate monolayer nickel inverse opals. (a) Gold was electron beam evaporated onto sapphire to make it conductive, (b) polystyrene spheres were selfassembled on the gold coated sapphire, (c) nickel was electrodeposited into the voids between polystyrene spheres to half the height of the monolayer, and (d) the polystyrene spheres were dissolved to produce the desired nickel structure for further atomic layer deposition alumina passivation.

Fig. 2: Custom sample mount for the high pressure and high temperature fouling tests. The design of the mount includes three sets of slits to hold samples within $5^{\circ}$ from vertical, a groove to avoid gravitational deposits from collecting near the bottom of the sample, and screw threads to help transfer the mount.

Fig. 3: (a) Thermogravimetric analysis (TGA) data for 1,6-bis(pyren-1-ylthio)hexane shown in the inset, and (b) differential scanning calorimetry (DSC) data for the same model asphaltene. The data in (a) showed two mass loss events, the first centered at $134.6^{\circ} \mathrm{C}$ and the second centered at $388.1^{\circ} \mathrm{C}$. The DSC data showed an exothermic peak at $75.8^{\circ} \mathrm{C}$ indicating a crystallization event, and an endothermic peak at $129.2^{\circ} \mathrm{C}$ indicating melting.

Fig. 4: X-ray photoelectron spectroscopy data for (a) polished and cleaned X65 substrate, and (b) polished and cleaned $30 \mathrm{~nm}$ thick atomic layer deposition (ALD) alumina coated X65 substrate. Using the Fe $2 p_{3 / 2}$ line, the surface chemistry of the X65 substrate was found to be a majority of $\mathrm{Fe}_{2} \mathrm{O}_{3}$ with $\mathrm{Fe}$ signal from the substrate. The surface chemistry of the ALD alumina coated $\mathrm{X} 65$ substrate was found to be $\mathrm{Al}_{2} \mathrm{O}_{3}$ with some aluminum hydroxide using the Al $2 p$ line.

Fig. 5: Scanning electron micrographs of atomic layer deposition (ALD) alumina coated on a $250 \mathrm{~nm}$ rough inverse opal (IO) template. (a) Plan view and section view (inset) of the as-deposited IOs. The scale bar is $500 \mathrm{~nm}$ for both (a) and its inset. (b) High magnification image of a strut as demarcated by a dashed square in (a) showing the conformal ALD alumina coating. The scale bar for (b) is $100 \mathrm{~nm}$. The deterministic geometry of the surface allows for easier correlation between surface roughness and deposit morphology.

Fig. 6: High pressure and high temperature fouling mass gain results for unpassivated and atomic layer deposition (ALD) alumina passivated X65 substrates. The dark blue squares represent unpassivated $X 65$ substrates fouled at $350^{\circ} \mathrm{C}$, the light blue squares represent unpassivated $\mathrm{X} 65$ substrates fouled at $150^{\circ} \mathrm{C}$, the dark blue circles represent ALD alumina passivated $\mathrm{X} 65$ substrates fouled at $350{ }^{\circ} \mathrm{C}$, and the light blue circles represent ALD alumina passivated $X 65$ substrates fouled at $150^{\circ} \mathrm{C}$. The total mass gain and its dependence on roughness was drastically reduced for the ALD passivated substrates.

Fig. 7: Scanning electron micrographs of (a) smooth $\mathrm{X} 65$ steel, (b) $250 \mathrm{~nm}$ rough inverse opal (IO), (c) $500 \mathrm{~nm}$ rough IO, and (d) $800 \mathrm{~nm}$ rough IO. All samples were passivated with atomic layer deposition alumina to reduce thermal creep and fouled at $150{ }^{\circ} \mathrm{C}$. The 
schematics shown in parts $(e)$ through $(f)$ illustrate the proposed mechanism to explain the observed correlation between deposit size and surface roughness in parts (a) through (d) respectively. Rougher IOs allow for larger deposits due to increased distance between physical barriers to deposit growth. The scale bar for (a) is $5 \mu \mathrm{m}$. All other scale bars are $2 \mu \mathrm{m}$.

Fig. 8: Scanning electron micrographs of (a) smooth and (c) rough unpassivated X65 steel; (d) smooth and (e) rough atomic layer deposition alumina passivated X65 steel after fouling at $350{ }^{\circ} \mathrm{C}$. The image in (a) shows the intersection between a delaminated and intact top deposit layer with a cross-section from the region demarcated with the dashed rectangle shown in (b). Larger, and more numerous deposits were found for the rough surfaces in comparison to the smooth surfaces with the same surface chemistry. The deposits in (a) were bi-layered. The protective focused ion beam platinum layer is labeled as $P t$. The scale bar is $5 \mu \mathrm{m}$ for (a), (c), (d) and (e). The scale bar for (b) is $2 \mu \mathrm{m}$.

Fig. 9: Scanning transmission electron micrographs of (a) smooth unpassivated X65 steel, and (b) smooth atomic layer deposition (ALD) alumina passivated X65 steel after fouling at $350{ }^{\circ} \mathrm{C}$. The sample in (a) was lifted out from a region where the top deposit layer was delaminated. A mixed deposit was observed in (a) with both "mat" and faceted regions. The deposits were weakly adhered to the surface as evidenced by several instances of surface porosity. No discernable deposits were seen in the ALD alumina passivated X65 substrate even with as low as a $5 \mathrm{~nm}$ thick passivation layer. The scale bars are $200 \mathrm{~nm}$. Part (c) is a selected area electron diffraction pattern of the faceted deposit demarcated with a dashed circle in (a) along the [121] zone. The deposit is identified as hexagonal pyrrhotite $\left(\mathrm{Fe}_{1-\mathrm{x}} \mathrm{S}\right)$.

Fig. 10: Box plot comparing the mass gain of atomic layer deposition alumina coated X65 substrates for different coating thicknesses. Three deposition regimes were identified: I) complete deposit coverage, II) partial deposit coverage, and III) full passivation where little deposition was observed. These regions correspond to coating thicknesses of 0 to $3.5 \mathrm{~nm}, 3.5$ to $5 \mathrm{~nm}$, and greater than $5 \mathrm{~nm}$ respectively. Digital images of representative samples from each of the three regions is also provided.

Fig. 11: X-ray photoelectron spectroscopy (XPS) data for $S 2 p$ core levels from (a) an unpassivated $\mathrm{X} 65$ dipped in the surrogate fuel at room temperature, (b) fouled unpassivated X65 substrate, and (c) fouled atomic layer deposition (ALD) alumina passivated $X 65$ substrate. The fouling temperature used for (b) and (c) was $350{ }^{\circ} \mathrm{C}$. The corresponding Fe $2 p$, Fe $2 p$, and Al $2 p$ core levels for the samples in parts (a), (b), and (c) are shown in parts (d), (e), and (f) respectively. The surface in (a) contained a thiol group in an unbound state and oxidized sulfur species (B.E. $=164.7 \mathrm{eV}$ ). The surface in (b) was found to contain a thiolate and sulfide in addition to the unbound thiol. The shift in the Fe 2p B.E. in part (e) compared to the unfouled state (cf Fig. 4 (a)) further supports the finding of a surface thiolate and sulfide. The surface in (c) was found to contain a metal sulfate. The spectra in parts (d) and (f) closely resemble the XPS data collected for the corresponding unfouled surfaces shown in Fig. 4, this indicates that the deposits on these surfaces are very thin. 


\section{FOR TABLE OF CONTENTS ONLY}
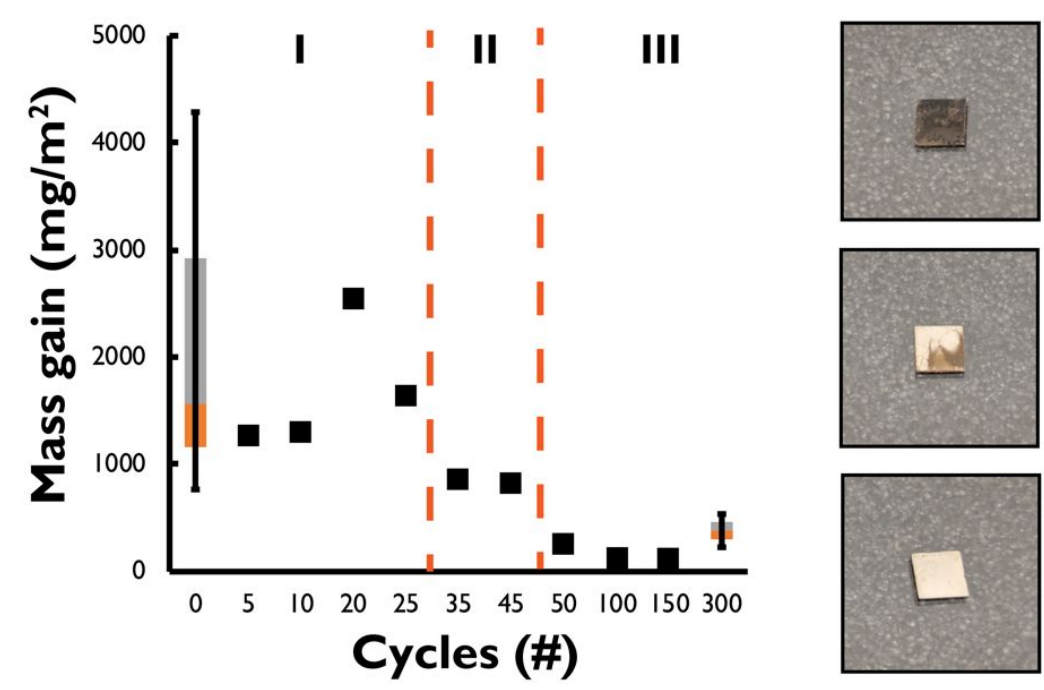

\section{Regime I}

Steel Corrosive attack Alumina

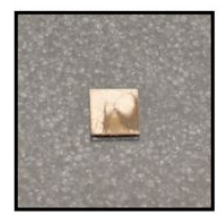

\section{Regime II}

Diffusion through coating
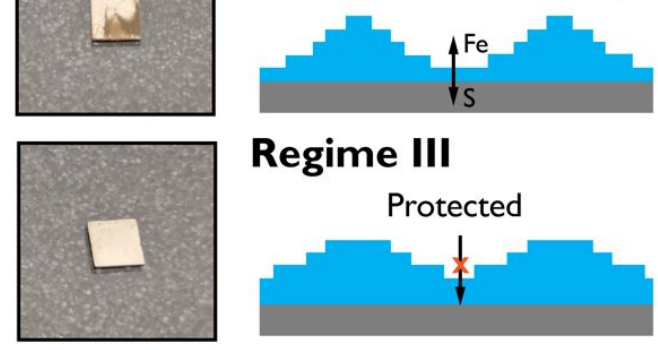

\section{Regime III}

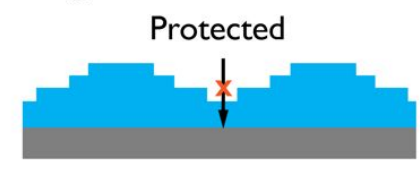


(a)

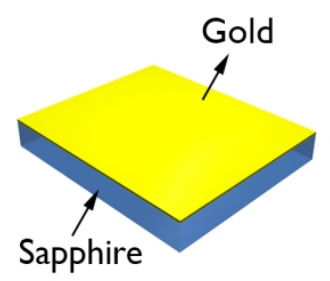

(b)

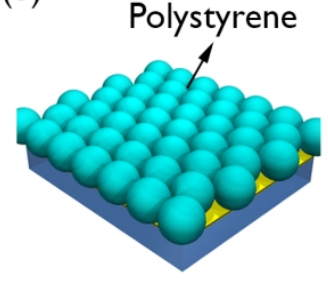

(c)

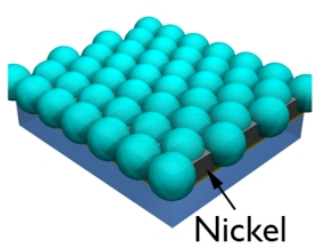

(d)

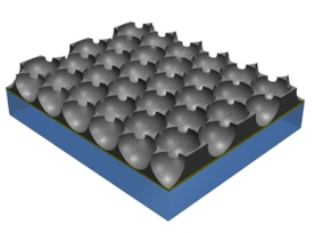

Fig. 1: Method used to fabricate monolayer nickel inverse opals. (a) Gold was electron beam evaporated onto sapphire to make it conductive, (b) polystyrene spheres were self-assembled on the gold coated sapphire, (c) nickel was electrodeposited into the voids between polystyrene spheres to half the height of the monolayer, and (d) the polystyrene spheres were dissolved to produce the desired nickel structure for further atomic layer deposition alumina passivation.

$$
152 \times 38 \mathrm{~mm}(300 \times 300 \text { DPI })
$$




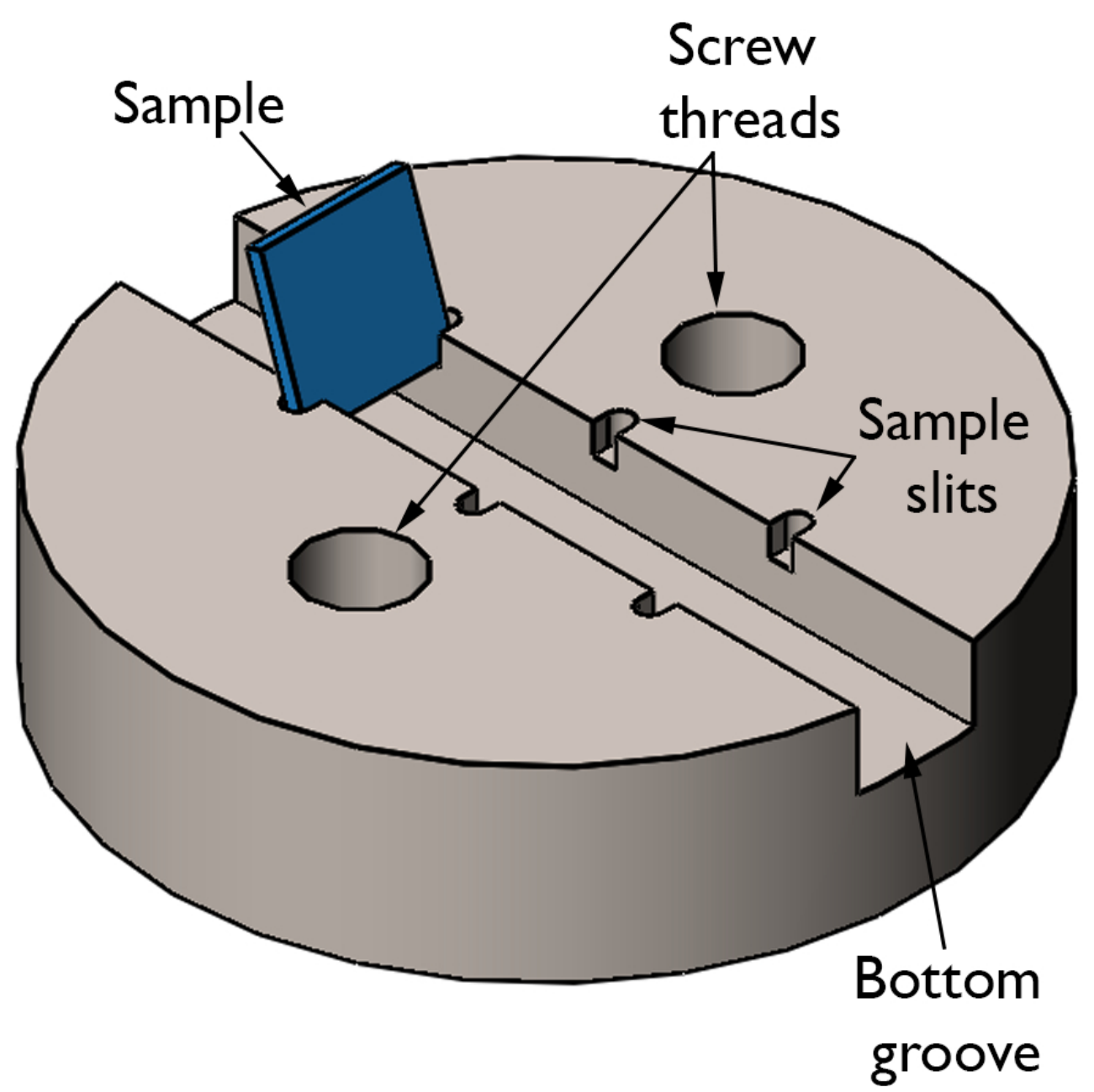

Fig. 2: Custom sample mount for the high pressure and high temperature fouling tests. The design of the mount includes three sets of slits to hold samples within $5^{\circ}$ from vertical, a groove to avoid gravitational deposits from collecting near the bottom of the sample, and screw threads to help transfer the mount.

$76 \times 76 \mathrm{~mm}(300 \times 300 \mathrm{DPI})$ 

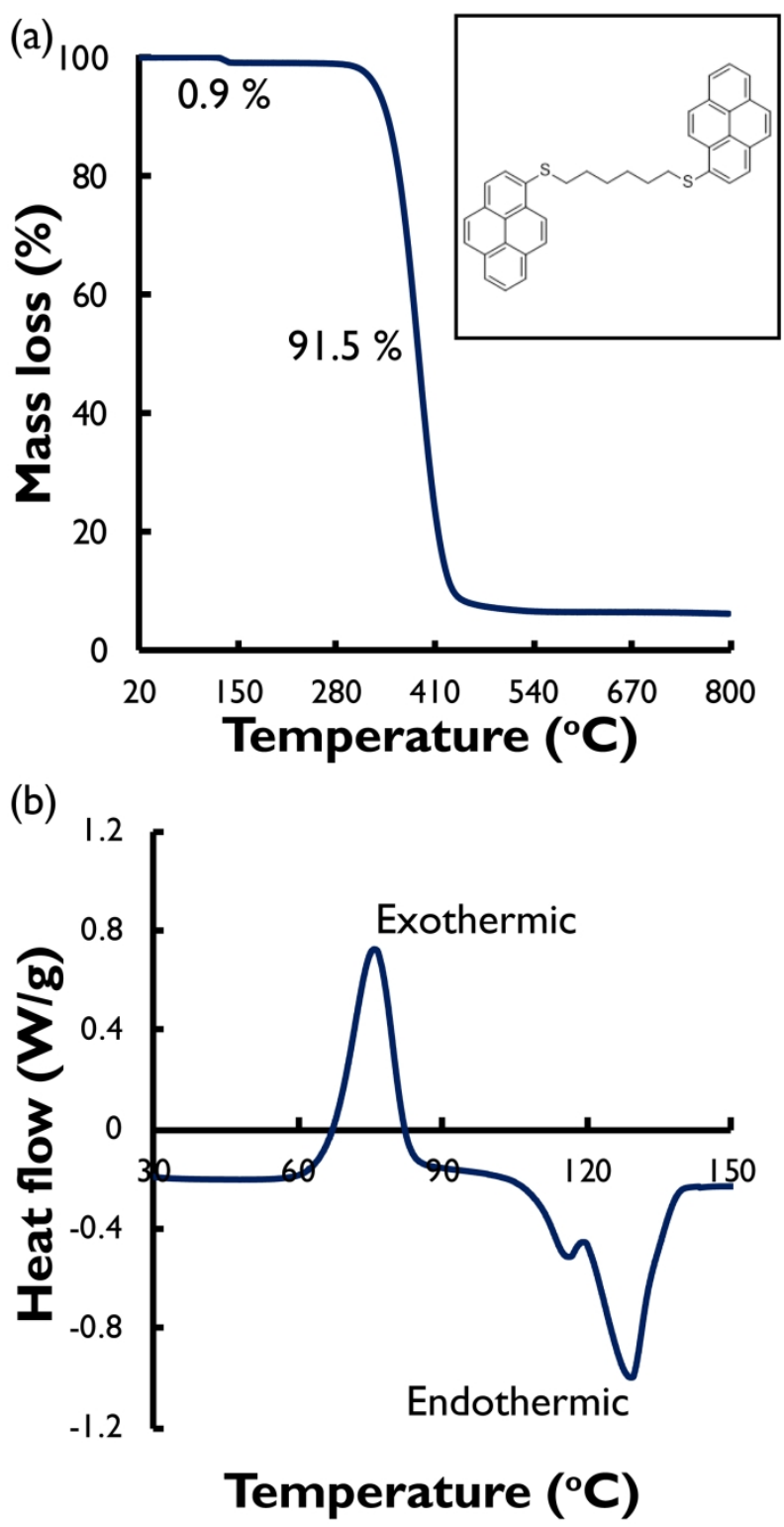

Fig. 3: (a) Thermogravimetric analysis (TGA) data for 1,6-bis(pyren-1-ylthio)hexane shown in the inset, and (b) differential scanning calorimetry (DSC) data for the same model asphaltene. The data in (a) showed two mass loss events, the first centered at $134.6^{\circ} \mathrm{C}$ and the second centered at $388.1^{\circ} \mathrm{C}$. The DSC data showed an exothermic peak at $75.8^{\circ} \mathrm{C}$ indicating a crystallization event, and an endothermic peak at $129.2^{\circ} \mathrm{C}$ indicating melting.

$76 \times 152 \mathrm{~mm}(600 \times 600 \mathrm{DPI})$ 


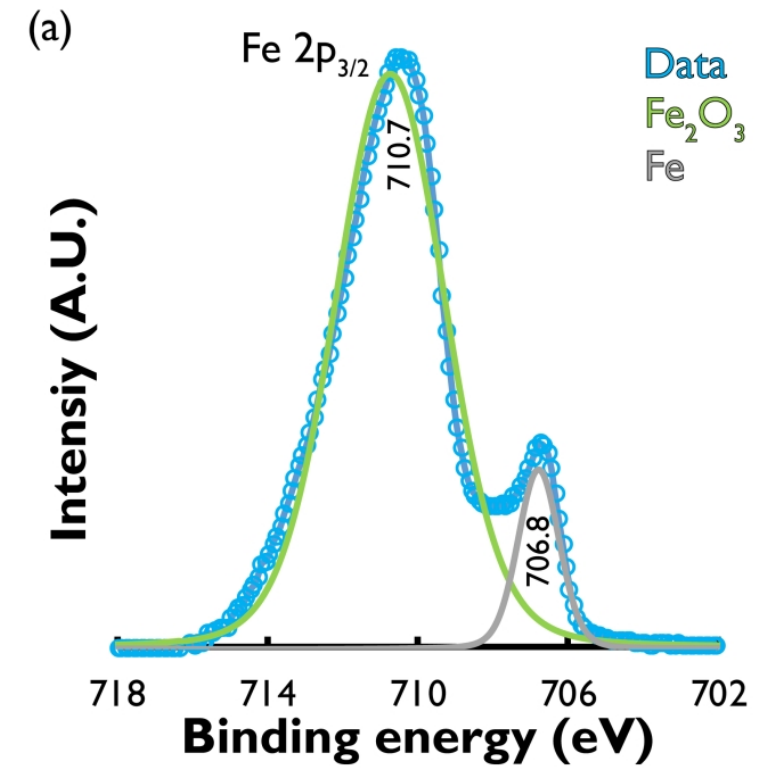

(b)

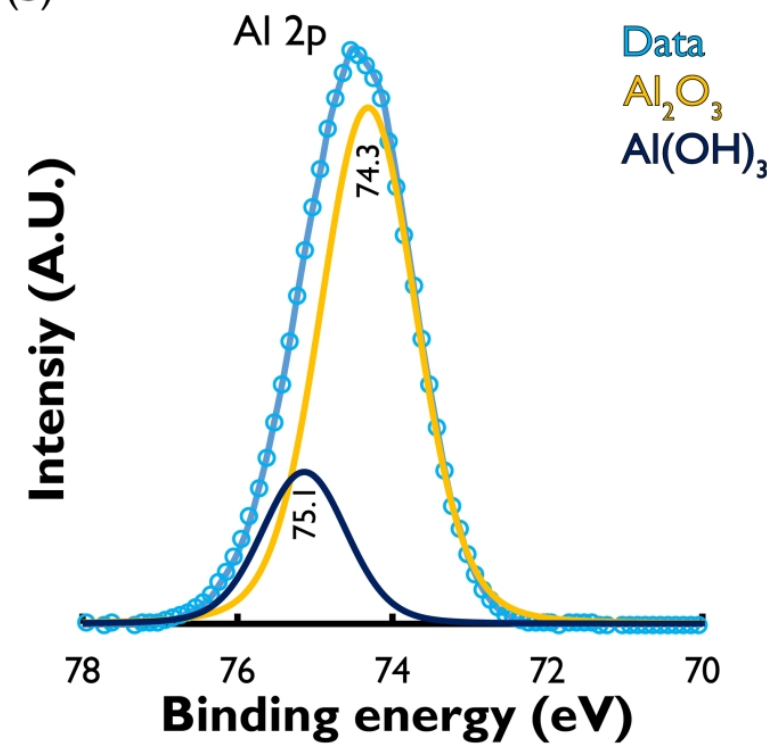

Fig. 4: X-ray photoelectron spectroscopy data for (a) polished and cleaned X65 substrate, and (b) polished and cleaned $30 \mathrm{~nm}$ thick atomic layer deposition (ALD) alumina coated X65 substrate. Using the Fe 2p3/2 line, the surface chemistry of the $\mathrm{X} 65$ substrate was found to be a majority of $\mathrm{Fe}_{2} \mathrm{O}_{3}$ with Fe signal from the substrate. The surface chemistry of the ALD alumina coated $\mathrm{X} 65$ substrate was found to be $\mathrm{Al}_{2} \mathrm{O}_{3}$ with some aluminum hydroxide using the Al $2 p$ line.

$76 \times 152 \mathrm{~mm}(600 \times 600 \mathrm{DPI})$ 


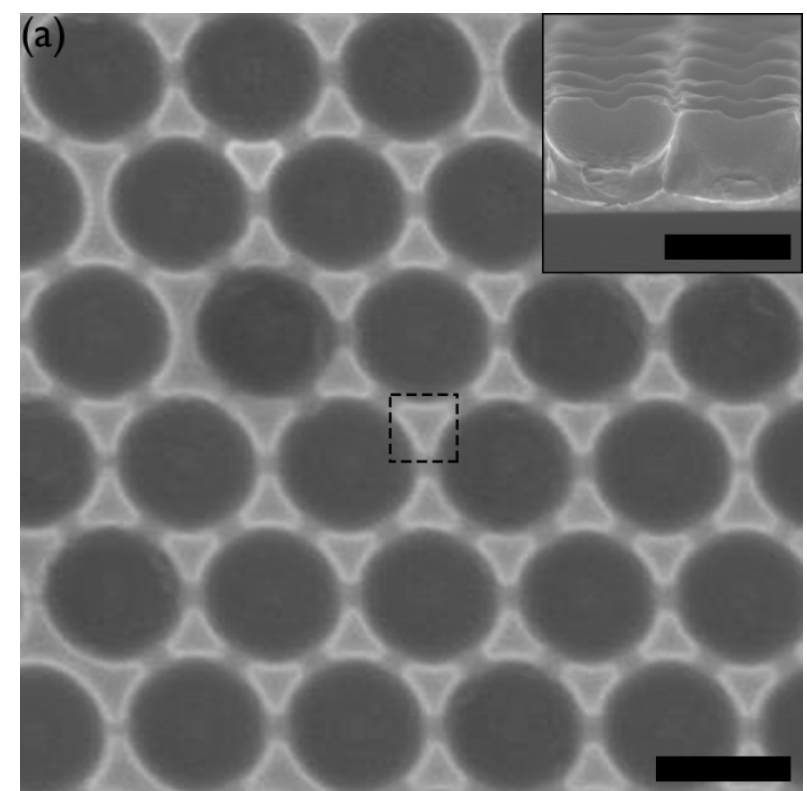

(b)

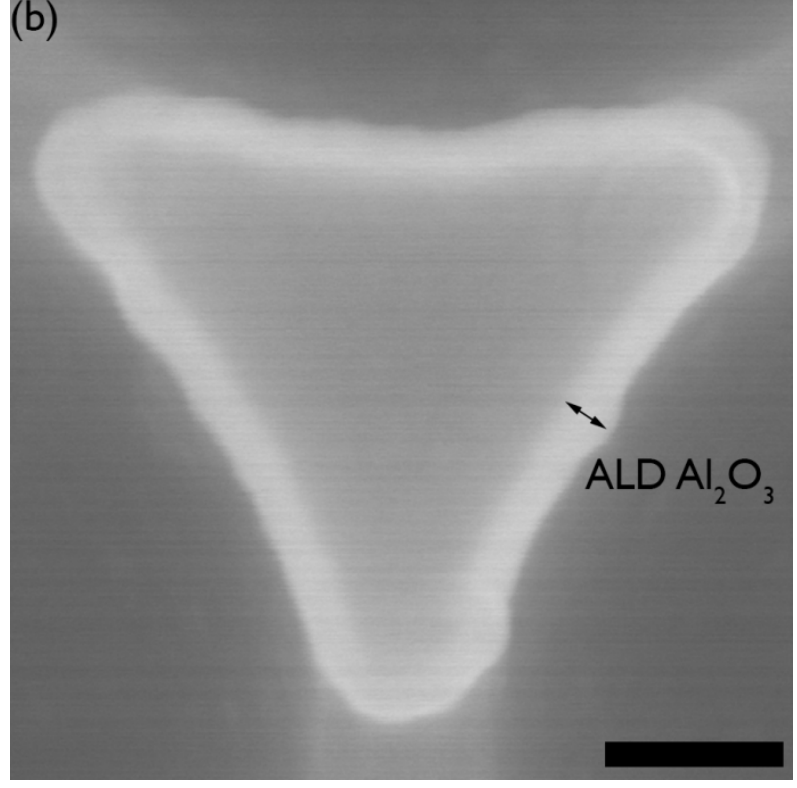

Fig. 5: Scanning electron micrographs of atomic layer deposition (ALD) alumina coated on a $250 \mathrm{~nm}$ rough inverse opal (IO) template. (a) Plan view and section view (inset) of the as-deposited IOs. The scale bar is $500 \mathrm{~nm}$ for both (a) and its inset. (b) High magnification image of a strut as demarcated by a dashed square in (a) showing the conformal ALD alumina coating. The scale bar for (b) is $100 \mathrm{~nm}$. The deterministic geometry of the surface allows for easier correlation between surface roughness and deposit morphology. 


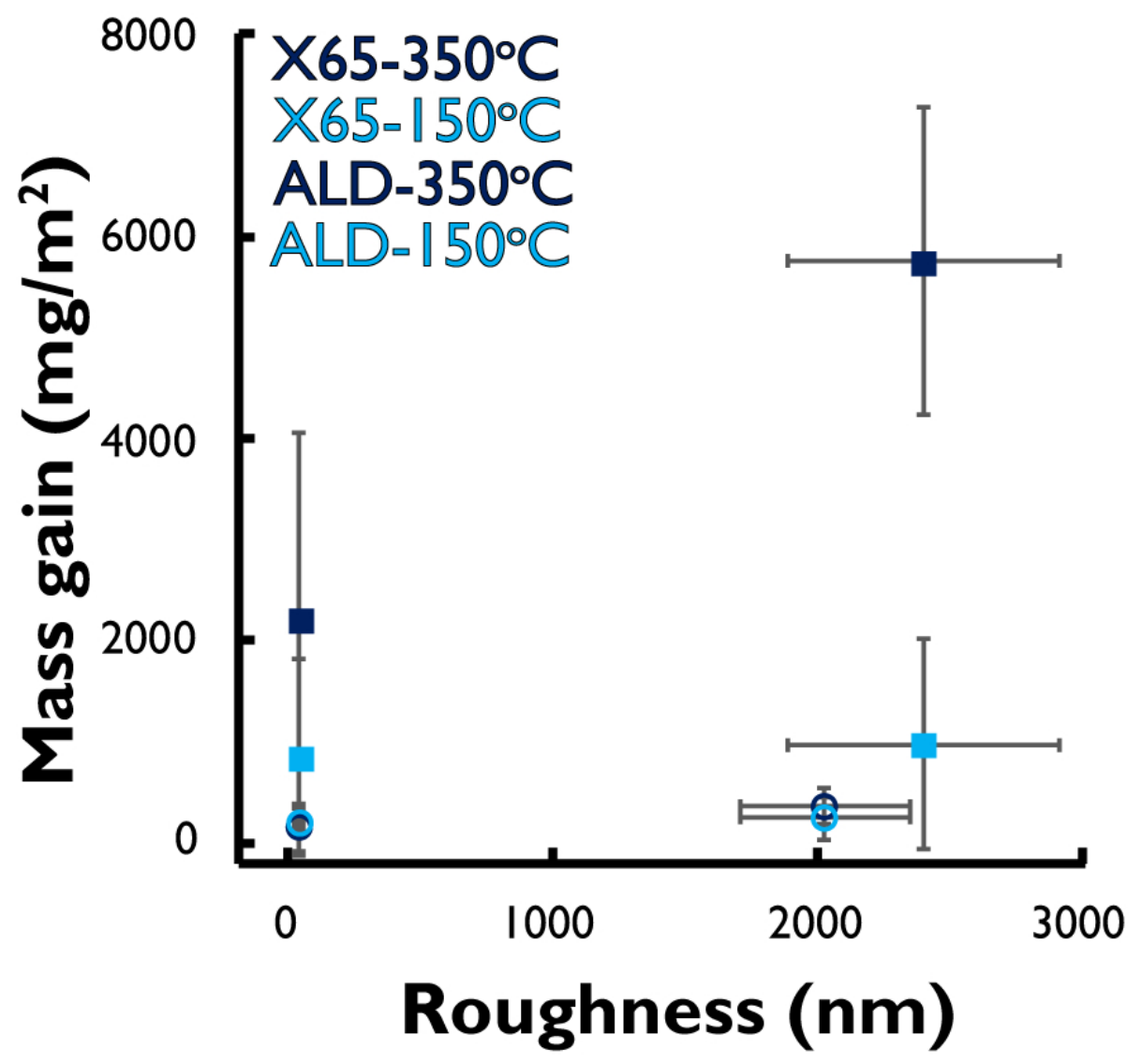

Fig. 6: High pressure and high temperature fouling mass gain results for unpassivated and atomic layer deposition (ALD) alumina passivated X65 substrates. The dark blue squares represent unpassivated X65 substrates fouled at $350 \mathrm{oC}$, the light blue squares represent unpassivated $\mathrm{X} 65$ substrates fouled at $150{ }^{\circ} \mathrm{C}$, the dark blue circles represent ALD alumina passivated $\mathrm{X} 65$ substrates fouled at $350{ }^{\circ} \mathrm{C}$, and the light blue circles represent ALD alumina passivated X65 substrates fouled at $150{ }^{\circ} \mathrm{C}$. The total mass gain and its dependence on roughness was drastically reduced for the ALD passivated substrates. 


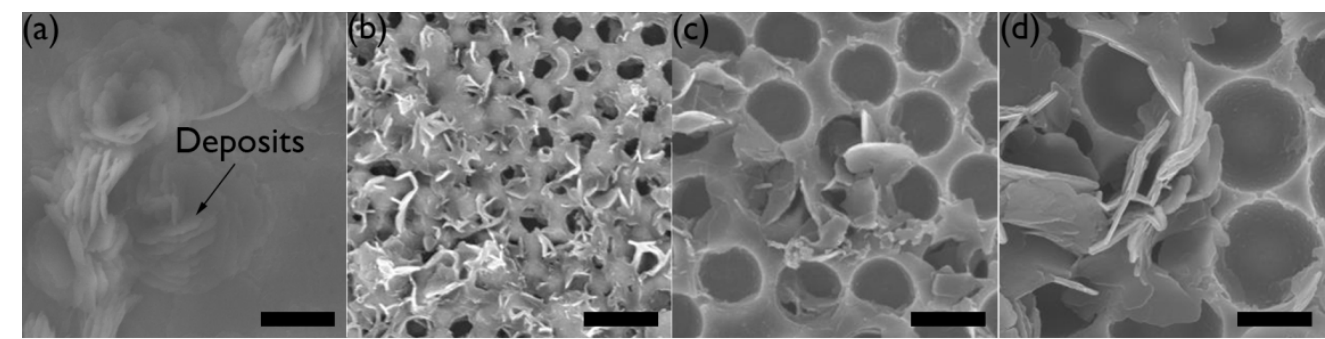

(e)

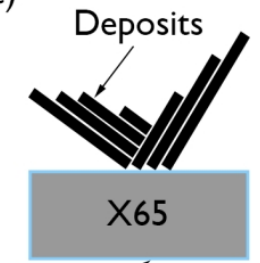

(f)

$250 \mathrm{~nm}$

(g)

$500 \mathrm{~nm}$

(h)
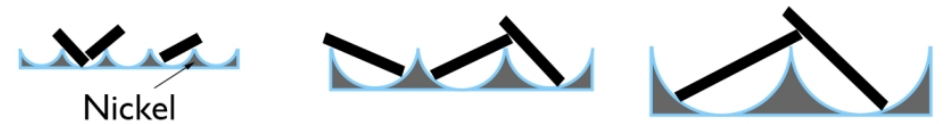

Alumina

Fig. 7: Scanning electron micrographs of (a) smooth $X 65$ steel, (b) $250 \mathrm{~nm}$ rough inverse opal (IO), (c) 500 $\mathrm{nm}$ rough IO, and (d) $800 \mathrm{~nm}$ rough IO. All samples were passivated with atomic layer deposition alumina to reduce thermal creep and fouled at $150 \mathrm{oC}$. The schematics shown in parts (e) through ( $\mathrm{f}$ ) illustrate the proposed mechanism to explain the observed correlation between deposit size and surface roughness in parts (a) through (d) respectively. Rougher IOs allow for larger deposits due to increased distance between physical barriers to deposit growth. The scale bar for (a) is $5 \mu \mathrm{m}$. All other scale bars are $2 \mu \mathrm{m}$.

$152 \times 76 \mathrm{~mm}(300 \times 300 \mathrm{DPI})$ 


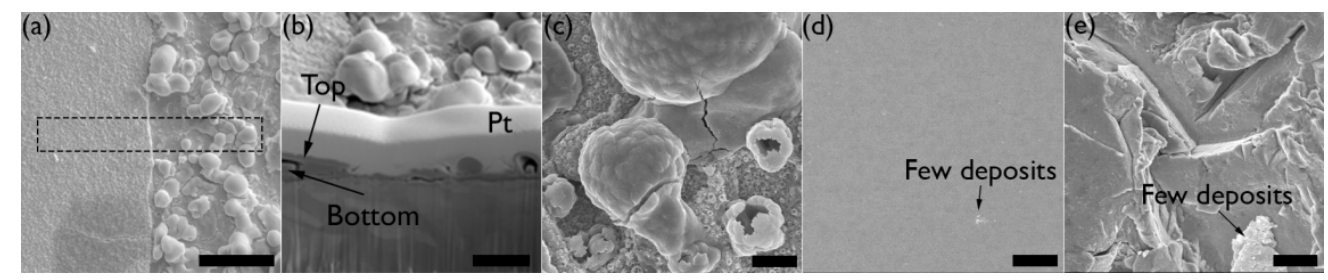

Fig. 8: Scanning electron micrographs of (a) smooth and (c) rough unpassivated X65 steel; (d) smooth and (e) rough atomic layer deposition alumina passivated $\times 65$ steel after fouling at $350^{\circ} \mathrm{C}$. The image in (a) shows the intersection between a delaminated and intact top deposit layer with a cross-section from the region demarcated with the dashed rectangle shown in (b). Larger, and more numerous deposits were found for the rough surfaces in comparison to the smooth surfaces with the same surface chemistry. The deposits in (a) were bi-layered. The protective focused ion beam platinum layer is labeled as Pt. The scale bar is 5 $\mu \mathrm{m}$ for (a), (c), (d) and (e). The scale bar for (b) is $2 \mu \mathrm{m}$.

$152 \times 30 \mathrm{~mm}(300 \times 300 \mathrm{DPI})$ 


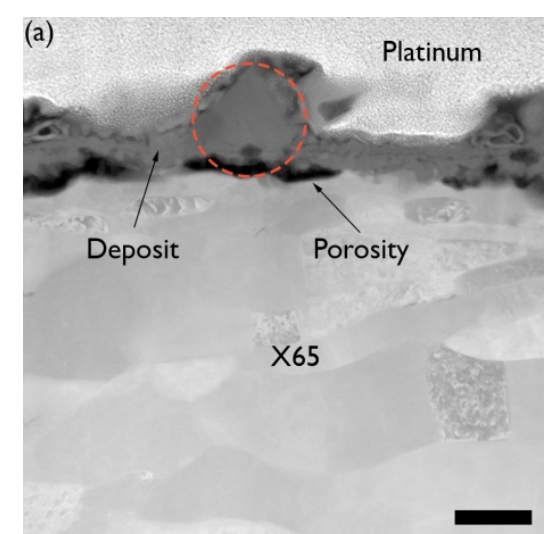

(b)
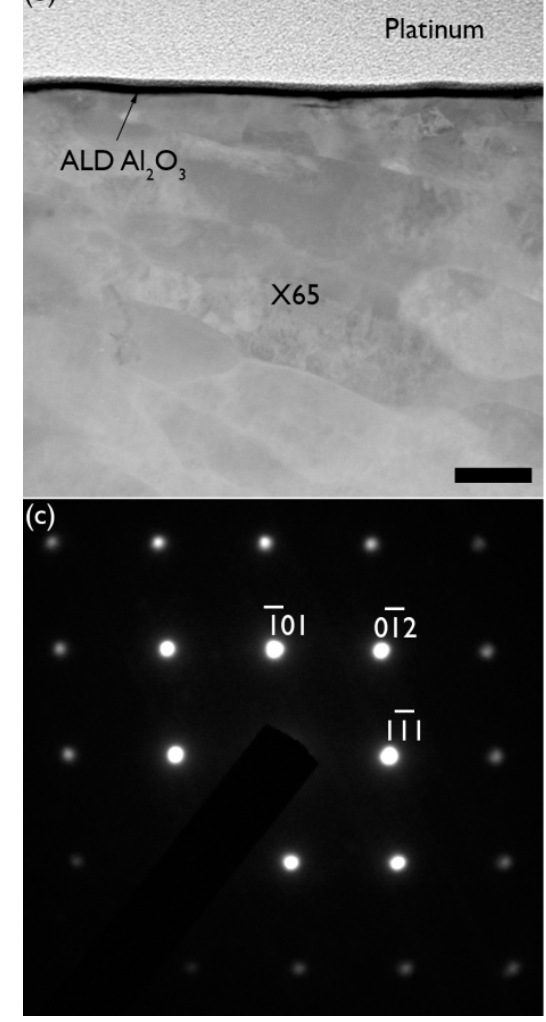

Fig. 9: Scanning transmission electron micrographs of (a) smooth unpassivated X65 steel, and (b) smooth atomic layer deposition (ALD) alumina passivated X65 steel after fouling at $350{ }^{\circ} \mathrm{C}$. The sample in (a) was lifted out from a region where the top deposit layer was delaminated. A mixed deposit was observed in (a) with both "mat" and faceted regions. The deposits were weakly adhered to the surface as evidenced by several instances of surface porosity. No discernable deposits were seen in the ALD alumina passivated X65 substrate even with as low as a $5 \mathrm{~nm}$ thick passivation layer. The scale bars are $200 \mathrm{~nm}$. Part (c) is a selected area electron diffraction pattern of the faceted deposit demarcated with a dashed circle in (a) along the [121] zone. The deposit is identified as hexagonal pyrrhotite ( $\left.\mathrm{Fe}_{1-x} \mathrm{~S}\right)$. 


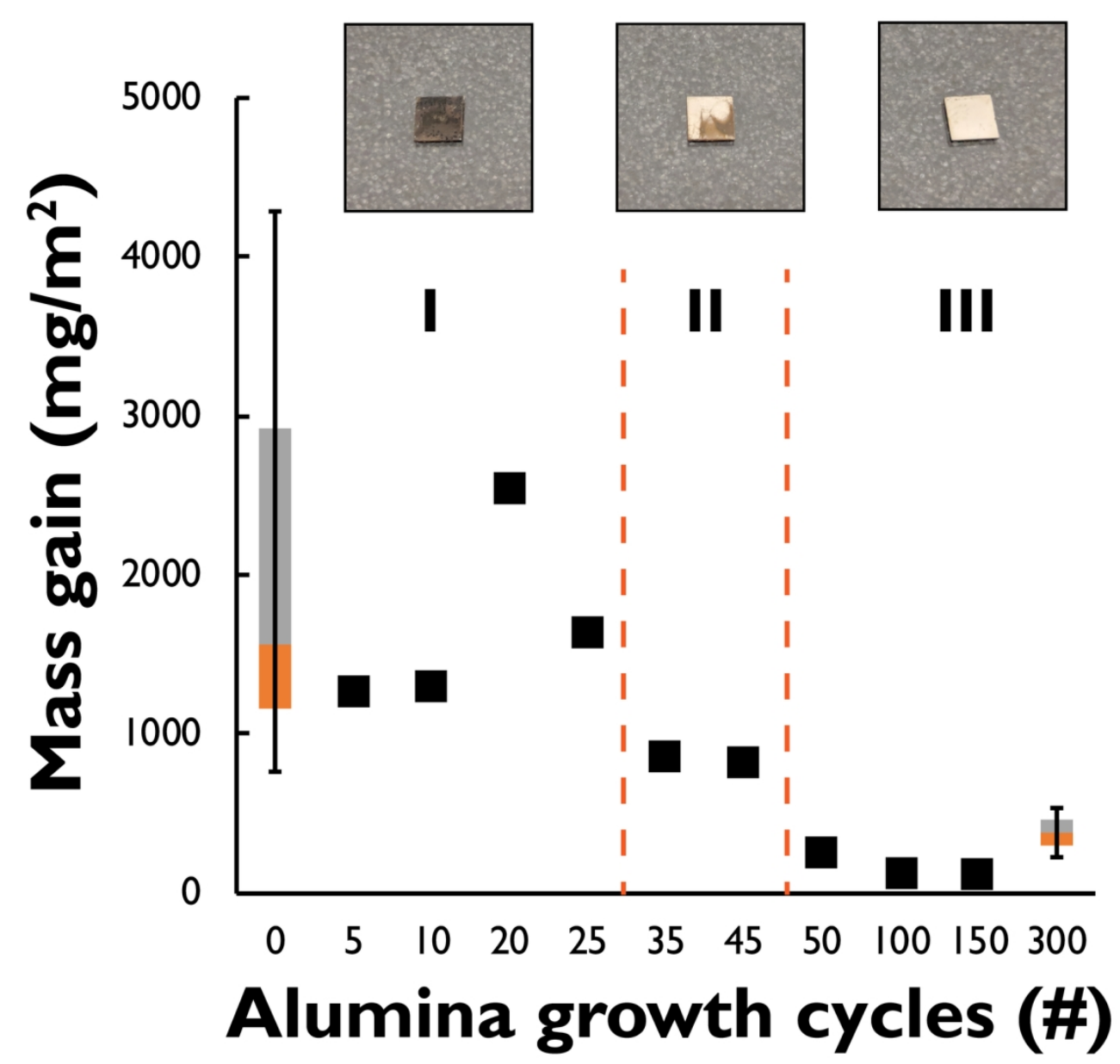

Fig. 10: Bar plot comparing the mass gain of atomic layer deposition alumina coated X65 substrates for different coating thicknesses. Three deposition regimes were identified: I) complete deposit coverage, II) partial deposit coverage, and III) full passivation where little deposition was observed. These regions correspond to coating thicknesses of 0 to $3.5 \mathrm{~nm}, 3.5$ to $5 \mathrm{~nm}$, and greater than $5 \mathrm{~nm}$ respectively. Digital images of representative samples from each of the three regions is also provided.

$$
76 \times 76 \mathrm{~mm}(600 \times 600 \mathrm{DPI})
$$



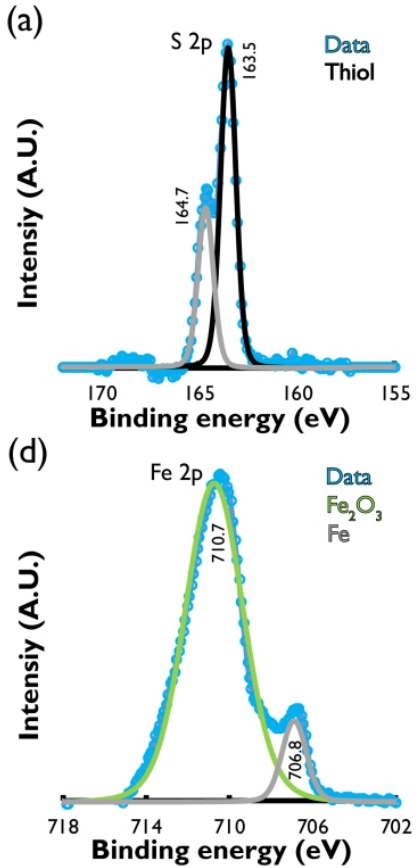

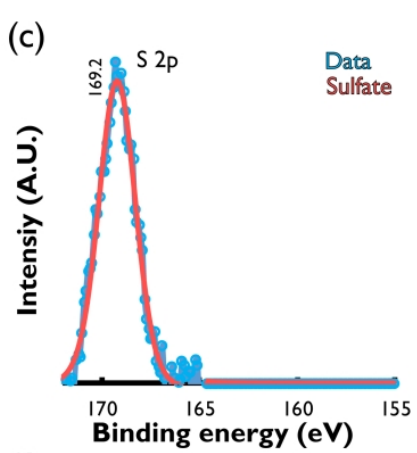

(e)
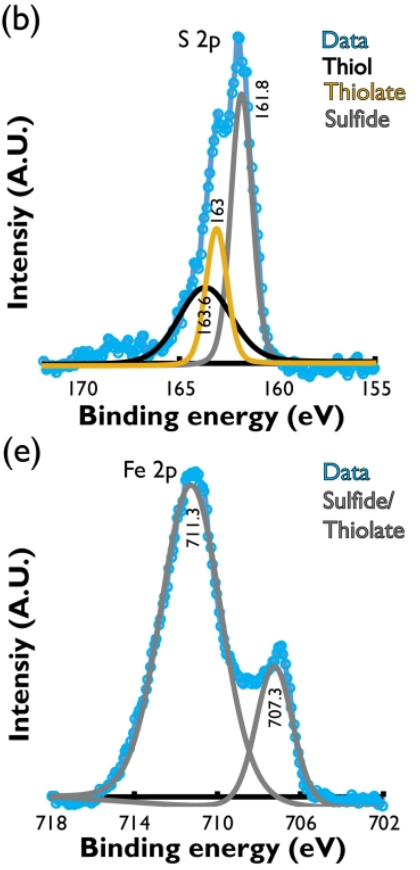

(f)

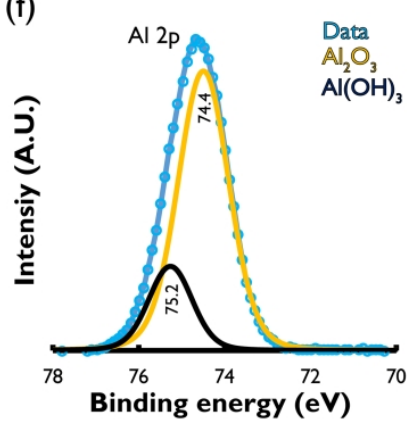

Fig. 11: X-ray photoelectron spectroscopy (XPS) data for $S 2 p$ core levels from (a) an unpassivated X65 dipped in the surrogate fuel at room temperature, (b) fouled unpassivated X65 substrate, and (c) fouled atomic layer deposition (ALD) alumina passivated X65 substrate. The fouling temperature used for (b) and (c) was $350^{\circ} \mathrm{C}$. The corresponding Fe 2p, Fe 2p, and Al 2p core levels for the samples in parts (a), (b), and (c) are shown in parts (d), (e), and (f) respectively. The surface in (a) contained a thiol group in an unbound state and oxidized sulfur species (B.E. $=164.7 \mathrm{eV}$ ). The surface in (b) was found to contain a thiolate and sulfide in addition to the unbound thiol. The shift in the Fe 2p B.E. in part (e) compared to the unfouled state (cf Fig. 4 (a)) further supports the finding of a surface thiolate and sulfide. The surface in (c) was found to contain a metal sulfate. The spectra in parts (d) and (f) closely resemble the XPS data collected for the corresponding unfouled surfaces shown in Fig. 4, this indicates that the deposits on these surfaces are very thin.

$152 \times 101 \mathrm{~mm}(600 \times 600 \mathrm{DPI})$ 

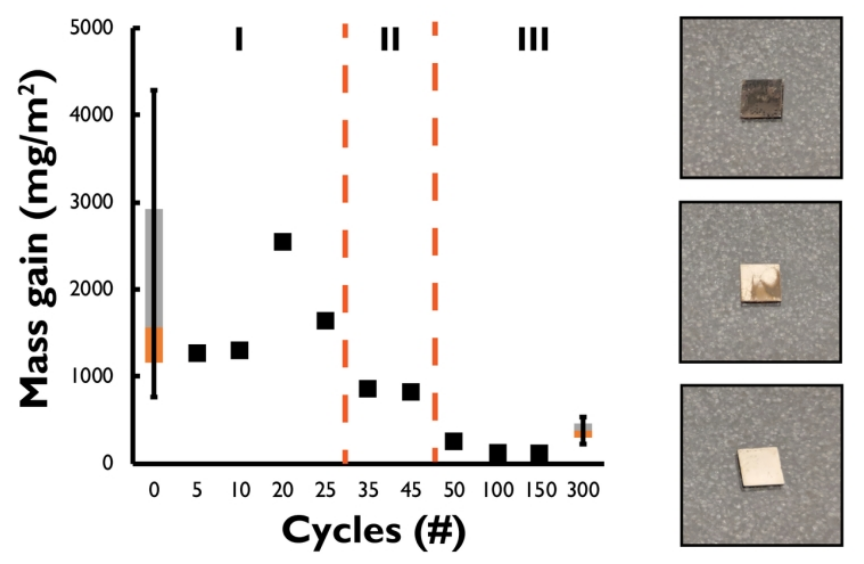

Regime I Steel

Corrosive attack Alumina

For Table of Contents Only

$82 \times 34 \mathrm{~mm}(600 \times 600 \mathrm{DPI})$
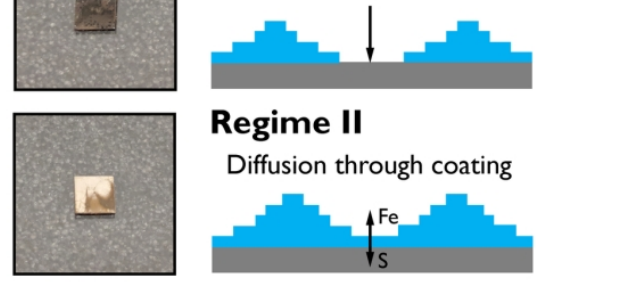

\section{Regime II}

Diffusion through coating
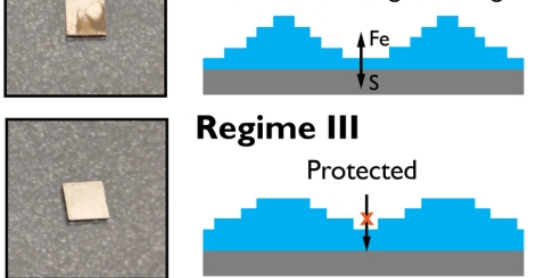

Regime III

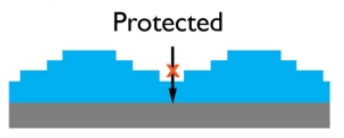

